\title{
HYBRID TAIL RISK AND EXPECTED STOCK RETURNS: WHEN DOES THE TAIL WAG THE DOG?
}

\author{
Turan G. Bali \\ Nusret Cakici \\ Robert F. Whitelaw \\ Working Paper 19460 \\ http://www.nber.org/papers/w19460 \\ NATIONAL BUREAU OF ECONOMIC RESEARCH \\ 1050 Massachusetts Avenue \\ Cambridge, MA 02138 \\ September 2013
}

We would like to thank seminar participants at Georgetown University, Hong Kong University of Science and Technology, and the University of Utah for helpful comments. The views expressed herein are those of the authors and do not necessarily reflect the views of the National Bureau of Economic Research.

NBER working papers are circulated for discussion and comment purposes. They have not been peerreviewed or been subject to the review by the NBER Board of Directors that accompanies official NBER publications.

(C) 2013 by Turan G. Bali, Nusret Cakici, and Robert F. Whitelaw. All rights reserved. Short sections of text, not to exceed two paragraphs, may be quoted without explicit permission provided that full credit, including $\odot$ notice, is given to the source. 
Hybrid Tail Risk and Expected Stock Returns: When Does the Tail Wag the Dog?

Turan G. Bali, Nusret Cakici, and Robert F. Whitelaw

NBER Working Paper No. 19460

September 2013

JEL No. C13,G10,G11

\begin{abstract}
$\underline{\text { ABSTRACT }}$
We introduce a new, hybrid measure of stock return tail covariance risk, motivated by the under-diversified portfolio holdings of individual investors, and investigate its cross-sectional predictive power. Our key innovation is that this covariance is measured across the left tail states of the individual stock return distribution, not across those of the market return as in standard systematic risk measures. We document a positive and significant relation between hybrid tail covariance risk (H-TCR) and expected stock returns, with an annualized premium of $9 \%$, in contrast to the insignificant or negative results for purely stock-specific or systematic tail risk measures.
\end{abstract}

Turan G. Bali

McDonough School of Business

Georgetown University

Between 37th and O Streets

Washington, D.C. 20057

tgb27@georgetown.edu

Nusret Cakici

Graduate School of Business

Fordham University

1790 Broadway

New York, NY 10019

cakici@fordham.edu
Robert F. Whitelaw

New York University

Stern School of Business

44 West 4th Street, Suite 9-190

New York, NY 10012-1126

and NBER

rwhitela@stern.nyu.edu 


\section{Introduction}

In spite of the dominance of the CAPM paradigm, there has been a longstanding interest in the literature on the question of whether downside or tail risk plays a special role in determining expected returns. Such a role could come about, for example, due to preferences that treat losses and gains asymmetrically, ${ }^{1}$ return distributions that are asymmetric, or some combination of the two. While systematic downside or tail risk is a natural starting point, there is increasing evidence that non-market risk may play an important role in determining the cross-section of expected returns. ${ }^{2}$ Thus, we consider a setting where investors hold concentrated stock holdings in addition to a fraction of their wealth in a well-diversified portfolio, e.g., a mutual fund within a retirement account, consistent with existing empirical evidence on the holdings of individual investors. ${ }^{3}$ In this setting the contribution of an individual stock to the tail risk of the portfolio can be decomposed into three components - a systematic component, a stock-specific component, and a third, hybrid component that depends on the co-tail risk of the stock and the market portfolio. Based on this decomposition, we conduct a thorough re-examination of the role of downside risk in determining the cross-section of expected returns. Specifically, controlling for the usual determinants of expected returns, we investigate the predictive power of various downside risk measures that vary across two dimensions: (i) the fraction of the lower half of the return distribution that they measure and on which they are calculated, i.e., the extent to which they are tail risk measures, and (ii) the extent to which they capture systematic versus idiosyncratic or total risk.

Our risk measures build on the notion of semi-variance or the lower partial moment (LPM) of Markowitz (1959). The LPM of an asset or portfolio is defined as

$$
L P M=\int_{-\infty}^{h}(R-h)^{2} f_{p}(R) d R,
$$

where $h$ is the target level of returns and $f_{p}(R)$ represents the probability density function of returns for portfolio $p .^{4}$ That is, the semi-variance is the expected value of the squared negative deviations from the mean, while the more general LPM uses a chosen point of reference $(h)$. The

\footnotetext{
${ }^{1}$ See, for example, Kahneman et al. (1990) for some of the extensive experimental evidence on loss aversion.

${ }^{2}$ For recent examples, see Ang et al. (2006, 2009) and Bali, Cakici and Whitelaw (2011).

${ }^{3}$ Polkovnichenko (2005), Van Nieuwerburgh and Veldkamp (2010).

${ }^{4}$ For expected utility maximizing investors, Bawa (1975) provides a theoretical rationale for using semi-variance or the lower partial moment as the measure of portfolio risk.
} 
main heuristic motivation for the use of the LPM in place of variance as a measure of risk is that the LPM measures losses (relative to some reference point), whereas variance depends on gains as well as losses. Of course, for symmetric distributions and a reference point equal to the mean of the distribution, this distinction is meaningless.

In our simplified setting in which investors hold an under-diversified portfolio consisting of positions in an individual stock and a diversified fund, three factors contribute to the tail risk of the portfolio. First, systematic tail risk matters in that the tail risk of the market portfolio contributes to the tail risk of the overall portfolio. We take our systematic risk measure from the mean-lower partial moment capital asset pricing model (EL-CAPM) of Bawa and Lindenberg (1977):

$$
\beta_{L P M}=\frac{E\left(\left[R_{i}-h\right]\left[R_{m}-h\right] \mid R_{m}<h\right)}{E\left(\left[R_{m}-h\right]^{2} \mid R_{m}<h\right)},
$$

where $E\left(R_{i}\right)$ is the expected return on asset $i, E\left(R_{m}\right)$ is the expected return on the market portfolio, $r_{f}$ is the risk-free interest rate, and $\beta_{L P M}$ is a measure of downside systematic risk for a target level of returns $h$. That is, the relevant beta in the model is the co-lower partial moment (CLPM) of the asset return with the market return divided by the LPM of the market return, where the moments are conditional on the market return being below a specified threshold.

Earlier studies on the EL-CAPM use alternative measures of downside market risk based on different return thresholds, such as the mean excess market return, the risk-free rate, or zero. ${ }^{5}$ More recently, Ang, Chen, and Xing (2006) re-examine these downside betas. Motivated by the possibility that it is more extreme negative realizations about which investors care or that it is asymmetries in the tail of return distributions that are important, we examine alternative measures of downside beta based on the observations in the lower tail of the market return distribution. There is recent evidence that systematic crash risk is priced in the cross-section of returns (Kelly (2010) and Spitzer (2006)), but these studies consider infrequent events of extreme magnitude, in the spirit of the rare disaster models of Rietz (1988) and Barro (2006), using empirical techniques from extreme value theory. In contrast, we consider the more frequent but less extreme tail events that occur on a regular basis, using more traditional risk measures.

\footnotetext{
${ }^{5}$ See, for example, Jahankhani (1976), Price, Price, and Nantell (1982), and Harlow and Rao (1989).
} 
Second, it is clear that the tail risk of the individual stock will also matter for the tail risk of the under-diversified portfolio. For stock-specific tail risk we use the LPM of individual stock returns.

Finally, we propose a new, hybrid measure of tail risk. Given that individual stocks generally have substantially higher volatilities than the market portfolio and assuming a sufficient weight in the stock in the portfolio, the tail events for such an under-diversified portfolio will coincide more with the tail events of the individual stocks than with the tail events of the diversified holdings. Thus, we construct a measure called hybrid tail covariance risk $(\mathrm{H}-$ TCR) defined as: ${ }^{6}$

$$
H-T C R_{i}=E\left(\left[R_{i}-h_{i}\right]\left[R_{m}-h_{m}\right] \mid R_{i}<h_{i}\right),
$$

where $h$ denotes the return threshold, e.g., the $10^{\text {th }}$ percentile of the return distribution of the stock or market. H-TCR is the CLPM between extreme daily returns on stock $i$ and the corresponding daily returns on the market portfolio, conditional on the stock return being below the specified threshold. H-TCR is analogous to the numerator of the EL-CAPM beta defined above except that the moment is conditional on the return on the individual stock rather than on the return on the market.

In our empirical analysis, we compute the above measures of tail risk (systematic, hybrid, and stock-specific) for individual stocks using six months and one year of daily data. We then ask which, if any, of these measures have predictive power for returns over the subsequent month using NYSE/AMEX/NASDAQ stocks over the July 1963-December 2009 sample period. In addition to the standard controls in cross-sectional tests, we are also careful to control for volatility (Ang et al. (2006, 2009)) and extreme returns (Bali, Cakici and Whitelaw (2011)) since these stock-specific distributional characteristics are likely to be correlated with both the LPM of stock returns and our hybrid measure of tail risk.

The results are striking. First, systematic risk has little or no explanatory power for future returns, whether measured relative to the center or the tail of the distribution. Second, stockspecific risk is, if anything, priced negatively, i.e., in the opposite direction of that implied by theory. However, these latter results should be interpreted with caution due to the difficulty of distinguishing any tail risk effect from the pricing of other distributional characteristics. Third,

\footnotetext{
${ }^{6}$ We motivate H-TCR more formally in the context of a stylized model in the next section.
} 
and most important, in marked contrast to these results, H-TCR has significant and robust positive predictive power for future returns.

Univariate portfolio level analyses indicate that a trading strategy that goes long stocks in the highest H-TCR decile and shorts stocks in the lowest H-TCR decile yields average raw and risk-adjusted returns of up to $9 \%$ per annum. Firm-level, cross-sectional regressions that control for well-known pricing effects, including size, book-to-market (Fama and French (1992, 1993)), momentum (Jegadeesh and Titman (1993)), short-term reversals (Jegadeesh (1990)), liquidity (Amihud (2002)), co-skewness (Harvey and Siddique (1999, 2000)), volatility (Ang et al. (2006, 2009)), and preference for lottery-like assets (Bali, Cakici, and Whitelaw (2011)) generate similar results. Moreover, there is strong evidence that the pricing of H-TCR is a tail risk, rather than a more general downside risk phenomenon, as the effect attenuates significantly as the fraction of observations used to calculate the measure increases.

As robustness checks, we test whether the positive relation between tail covariance risk and the cross-section of expected returns holds in bivariate dependent sorts, using size and bookto-market matched benchmark portfolios similar to Daniel and Titman (1997), and once we screen for extreme stocks across numerous dimensions. Throughout our empirical analysis, the evidence is consistent with significant pricing effects generated by individual investors who care about how the tail risk of their concentrated positions interacts with their diversified holdings.

The paper is organized as follows. Section 2 motivates our tail covariance risk measure in the context of a stylized model and also presents motivating empirical evidence. Section 3 contains the data and variable definitions. Section 4 presents evidence of cross-sectional predictability in the context of univariate portfolio sorts and also looks more closely at the characteristics of the stocks within these portfolios. Section 5 examines the significance of a cross-sectional relation between tail covariance risk and expected stock returns using firm-level regressions. Section 6 provides bivariate portfolio level analyses, controlling for size, book-tomarket, momentum, short-term reversals, liquidity, co-skewness, volatility, and extreme returns, while also examining the predictive power of tail covariance risk using the characteristic matched benchmark portfolios. Section 7 provides additional robustness checks, and Section 8 concludes. 


\section{Motivating Theory and Empirical Evidence}

In order to motivate our three measures of tail risk, we develop a relatively stylized, 1-period, discrete state space model in which systematic, stock-specific and hybrid tail risk arise as appropriate measures of risk for an individual stock. The assumptions of this model are, in turn, motivated by existing empirical evidence on the stock holdings of individual investors.

Although diversification is critical in eliminating idiosyncratic risk, a closer examination of the portfolios of individual investors suggests that these investors are, in general, not welldiversified. ${ }^{7}$ For example, Polkovnichenko (2005) examines a survey of 14 million households and shows that the median number of stocks in household portfolios is two in 1989, 1992, 1995, and 1998. The median increases to three stocks in 2001. Based on 40,000 stock accounts at a brokerage firm, Goetzmann and Kumar (2008) find that the median number of stocks in a portfolio of individual investors is three in the 1991-1996 period. These results are similar to the findings of earlier studies. For example, Blume and Friend (1975) and Blume, Crockett, and Friend (1974) provide evidence that the average number of stocks in household portfolios is about 3.41 in 1967. Odean (1999) and Barber and Odean (2001) also report the median number of stocks in individual investors' portfolios as two to three. In recent work, Dorn and Huberman (2005, 2010) use trading records between 1995 and 2000 of over 20,000 customers of a German discount brokerage and find that the typical portfolio consists of little more than three stocks.

However, these individual stock holdings often do not constitute the full financial asset portfolios of these investors. Polkovnichenko (2005) reports the fraction of individual equities relative to total financial assets as $33 \%$ in $1989,39 \%$ in $1992,49 \%$ in $1995,53 \%$ in 1998 , and $57 \%$ in 2001. That is, investors have a significant fraction of their wealth in concentrated holdings, but they also hold wealth in other investments that may take the form, for example, of diversified mutual funds in retirement accounts.

Based on this evidence, consider an investor that holds a portfolio consisting of positions in two assets-equity in an individual firm and the market portfolio. Assume that over the next period the returns on the firm $\left(R_{i}\right)$ and on the market $\left(R_{m}\right)$ can take on $J$ and $K$ discrete values, respectively, indexed by $j=1, \ldots, J$ and $k=1, \ldots, K$ and in order of increasing returns. That is, the

\footnotetext{
${ }^{7}$ It is important to note that this under-diversification relative to the implications of classical models of portfolio choice could be completely consistent with rationality in more complex models. For example, Roche et al. (2013), Van Nieuwerburgh and Veldkamp (2010), and references therein propose a number of rational models that generate concentrated holdings.
} 
return in state $j$ on firm $i$ is greater that the return in state $j-1\left(R_{i, j}>R_{i, j-1}\right)$ and similarly for the market $\left(R_{m, k}>R_{m, k-1}\right)$. There are $J \times K$ possible states of the world, each occurring with probability $p_{j k}$, where the probability of a given state can be zero. Denote the investor's non-negative portfolio weights in the two assets as $w_{i}$ and $w_{m}$, where $w_{i}+w_{m}=1$. The portfolio return in each state is

$$
R_{P, j k}=w_{i} R_{i, j}+\left(1-w_{i}\right) R_{m, k} .
$$

Now assume further that the relevant measure of risk is the LPM of the portfolio, as defined in equation (1), for a specified threshold $h$. This calculation requires an ordering of the $J$ $\mathrm{x} K$ states in terms of the associated portfolio return in order to compute the probability-weighted sum of the states with returns less than $h$, but the portfolio return and therefore the ordering depends on both the magnitudes of the returns on the two assets in each state and the portfolio weights. A simple numerical example is sufficient to illustrate this point. Consider two states, one with a firm return of $-20 \%$ and a market return of $-10 \%$, the second with firm and market returns of $-15 \%$. For relatively larger (smaller) fractions invested in the firm, the former will have a lower (higher) portfolio return than the latter as illustrated in the table below.

\begin{tabular}{cccccc}
\hline State & $w_{i}$ & $w_{m}$ & $R_{i}$ & $R_{m}$ & $R_{P}$ \\
\hline 1 & 0.6 & 0.4 & $-20 \%$ & $-10 \%$ & $-16 \%$ \\
2 & 0.6 & 0.4 & $-15 \%$ & $-15 \%$ & $-15 \%$ \\
1 & 0.4 & 0.6 & $-20 \%$ & $-10 \%$ & $-14 \%$ \\
2 & 0.4 & 0.6 & $-15 \%$ & $-15 \%$ & $-15 \%$ \\
\hline
\end{tabular}

In spite of this dependence on the model parameters, there are some things that can be said about the relevant measures of tail risk in this setting. First, holding all else fixed, the more extreme the negative returns on the firm, the larger is the LPM of the portfolio, i.e., the greater the tail risk. Due to the under-diversified nature of the portfolio, stock-specific risk matters. In the context of tail risk, a natural measure of this stock-specific risk is the LPM of the stock return:

$$
\operatorname{LPM}\left(R_{i}\right)=\sum_{R_{i}<h_{i}}\left(R_{i}-h_{i}\right)^{2}
$$


Second, again holding all else fixed, the more extreme the negative returns on the market, the larger is the LPM of the portfolio. Therefore, in addition to the stock-specific risk, a stock is risky to the extent that it contributes to the tail risk of the market portfolio. The natural measure of this component of risk is the beta in the EL-CAPM setting:

$$
\beta_{i, L P M}=\frac{\sum_{R_{m}<h_{m}}\left(R_{i}-h_{m}\right)\left(R_{m}-h_{m}\right)}{\sum_{R_{m}<h_{m}}\left(R_{m}-h_{m}\right)^{2}} .
$$

Third, and perhaps most interesting, is the risk component associated with co-movement of the firm and the market in the tail of the distribution of the portfolio return. If the tail events for the firm and the market coincide, then these states will also be the tail states for the portfolio return, and the LPM of the portfolio will be high. On the other hand, if they do not coincide, then we need to develop an easily implementable empirical proxy for this co-movement. As noted above, the identity of the tail states for the portfolio depends on the model parameters that determine the ordering of the returns across states. State $(j=1, k=1)$ is obviously the state with the lowest portfolio return independent of portfolio weights. The next lowest return state is either $(j=1, k=2)$ or $(j=2, k=1)$ with returns

$$
\begin{aligned}
& R_{P, 12}=w_{i} R_{i, 1}+\left(1-w_{i}\right) R_{m, 2} \\
& R_{P, 21}=w_{i} R_{i, 2}+\left(1-w_{i}\right) R_{m, 1}
\end{aligned} .
$$

The former will have the lower return as long as

$$
w_{i}\left(R_{i, 2}-R_{i, 1}\right)>\left(1-w_{i}\right)\left(R_{m, 2}-R_{m, 1}\right) .
$$

This simple inequality generates some insight. Specifically, conditioning on states with low firm returns (as opposed to low market returns), i.e., selecting $(j=1, k=2)$ versus $(j=2, k=1)$, is the intuitively correct thing to do as long as the firm is more volatile than the market. The difference between returns across discrete states is the analogue to volatility, and, as long as the weight in the firm is sufficiently high, the set of low portfolio return states will be those with low firm returns and varying market returns rather than low market returns and varying firm returns. This intuition motivates the construction of our hybrid measure of tail risk, which we call hybrid tail covariance risk (H-TCR). Specifically, we define

$$
H-T C R=\sum_{R_{i}<h_{i}}\left(R_{i}-h_{i}\right)\left(R_{m}-h_{m}\right) .
$$


The key distinction between this measure and the LPM beta in equation (6) is that H-TCR conditions on the states of the world with low stock returns, not low market returns. Note that for the purposes of cross-sectional analyses, the denominator in equation (6) is irrelevant since it is equal across all stocks; it simply serves to normalize the systematic risk measure.

As a check on the possible economic impact of this distinction, we perform a simple empirical exercise. For each month, six months or one year of past daily returns (approximately 125 or 250 daily observations, respectively) are used to determine the tail observations for the market portfolio and also for individual stocks at the $10 \%$ level, i.e., we identify the 13 or 25 days on which the market fell the most, and we also identify separately the 13 or 25 days on which each individual stock fell the most. We then count the number of days that these two sets have in common for each individual stock. The table below shows percentiles for the number of common days over the 1962-2009 sample period. For both sample lengths, the median number of common days is small, 2.77 and 5.52 for six months and one year, respectively, an overlap of only approximately $20 \%$ between the tails of the market return distribution and that of a typical stock in both cases. Even the $99^{\text {th }}$ percentiles for the number of common days are only 7.17 and 12.61 (an overlap of approximately 50\%). Clearly the tail events for the market and individual stocks do not coincide. In other words, tail events for individual stocks are primarily idiosyncratic. Thus, there is a realistic possibility that H-TCR will differ significantly from downside beta and, moreover, that this risk measure will better capture tail risk for investors with meaningful fractions of their wealth in concentrated positions.

\section{Percentiles for the Number of Common Days in the 10\% Tail}

\begin{tabular}{cccccccccc} 
& $1 \%$ & $5 \%$ & $10 \%$ & $30 \%$ & $50 \%$ & $70 \%$ & $90 \%$ & $95 \%$ & $99 \%$ \\
\hline 6 months & 0.02 & 0.42 & 0.87 & 1.87 & 2.77 & 3.75 & 5.14 & 5.88 & 7.17 \\
12 months & 0.65 & 1.73 & 2.38 & 4.09 & 5.52 & 7.04 & 9.37 & 10.53 & 12.61 \\
\hline
\end{tabular}

We also look directly at the empirical, cross-sectional determinants of the LPM of a concentrated portfolio of the type described in equation (4). Again using daily returns over a six month or one year period, the LPM of the portfolio is calculated as

$$
\operatorname{LPM}\left(R_{p}\right)=\sum_{R_{p}<h_{p}}\left(R_{p}-h_{p}\right)^{2}
$$


where the sum is taken over the days for which the portfolio return is less than the specified threshold. Intuitively, this portfolio LPM will depend on the three components of tail risk discussed above — systematic, stock-specific, and hybrid.

We consider two sets of portfolios weights- $50 \%$ in the stock and $50 \%$ in the market, and $30 \%$ in the stock and $70 \%$ in the market - and thresholds at the $10^{\text {th }}$ percentile of the relevant return distributions. Each month, we look back over the preceding 6 or 12 months and calculate the four quantities in equations (5), (6), (9), and (10). We then run firm-level Fama-MacBeth cross-sectional regressions of $\operatorname{LPM}\left(R_{p}\right)$ on $\operatorname{LPM}\left(R_{i}\right), \beta_{i, L P M}$, and $H-T C R_{i}$ for each month from July 1963 to December 2009:

$$
L P M_{i, t}^{p}=\lambda_{0, t}+\lambda_{1, t} L P M_{i, t}+\lambda_{2, t} \beta_{i, L P M, t}+\lambda_{3, t} H-T C R_{i, t}+\varepsilon_{i, t} .
$$

For brevity we only discuss the results for the one year sample length, but the results using six months are similar. For the 50/50 weights, the average slope coefficient on $L P M_{i}$ is estimated to be 0.26 with a Newey-West t-statistic of 208.9, the average coefficient on $H-T C R_{i}$ is 0.33 with a t-statistic of 36.3 , and the average coefficient on $\beta_{i, L P M}$ is 0.0003 with a t-statistic of 3.0. All the coefficients are statistically significant, but the magnitudes of the t-statistics indicate their marginal explanatory power. The average $R$-squared of the monthly cross-sectional regressions in equation (11) is $98.5 \%$, i.e., the three tail risk measures capture almost all the cross-sectional variation in portfolio LPM. For the 30/70 weights, the average estimated slope coefficient on $L P M_{i}$ is lower, 0.09 , with a t-statistic of 104.9 , because the investor allocates a smaller amount to the individual stock. The average coefficient on $H-T C R_{i}$ is also lower at 0.23 with a t-statistic of 40.2 , while that on $\beta_{i, L P M}$ is higher at 0.0004 , with a corresponding t-statistic of 3.4. The average $R$-squared of the monthly cross-sectional regressions is $95.1 \%$. In both cases, the significance of the coefficient on H-TCR and the high explanatory power of the crosssectional regressions validate our choice of the hybrid tail risk measure. Moreover, while variations of the H-TCR measure give similar results, these variations generally yield lower cross-sectional $R$-squareds than those for H-TCR.

Overall, these empirical results indicate that H-TCR is an appropriate measure of risk in our framework. Theoretically, the dependence of H-TCR on the CLPM of firm and market returns follows from the assumption that the LPM of the portfolio return is the correct measure of risk at the portfolio level. Finally, as is true with any model that assumes concentrated 
holdings, the total risk of these individual assets will also contribute to portfolio risk and therefore may require compensation in equilibrium.

\section{Data and Variable Definitions}

The first dataset includes all New York Stock Exchange (NYSE), American Stock Exchange (AMEX), and NASDAQ financial and nonfinancial firms from the Center for Research in Security Prices (CRSP) for the period from July 1962 through December $2009 .{ }^{8}$ We use daily stock returns to estimate alternative measures of risk. The second data set is COMPUSTAT, which is primarily used to obtain the book values for individual stocks.

For each month from July 1963 to December 2009, we compute the three tail risk measures for each firm in the sample-(1) the LPM of the return on the stock, (2) the LPM beta of the stock with respect to the market, and (3) hybrid tail covariance risk, as defined in equations (5), (6), and (9), respectively. In all cases we use daily returns over the past six months, except for certain extensions in Section 5, and the return thresholds for the stock and market return are determined by the relevant empirical percentiles over the same sample. For much of the analysis we employ the $10^{\text {th }}$ percentile as our measure of the tail of the distribution, but we also report results for thresholds ranging from the $5^{\text {th }}$ percentile to the $50^{\text {th }}$ percentile.

We also employ an extensive set of control variables. As Subrahmanyam (2010) points out, over 50 variables have been shown to have predictive power for stock returns in the crosssection. It is infeasible to control for all of these variables, but we select both the most popular variables in the literature and those that, intuitively, are most likely to be correlated with our tail risk measures. The first four variables are those from the Fama-French-Carhart 4-factor modelmarket beta, size, book-to-market, and momentum. We also control for microstructure-related phenomena in the form of short-term reversals and liquidity. Finally we include three variablesco-skewness, idiosyncratic volatility, and extreme positive returns - that are directly related to the distribution of returns, and thus possibly tail risk as well, and that have been shown to have significant predictive power. The detailed definitions of all these variables are provided in the Appendix.

\footnotetext{
${ }^{8}$ Following Harris (1994), Jegadeesh and Titman (2001), and Ang, Chen, and Xing (2006), we remove small, illiquid, and low-priced stocks from the sample. Specifically, for each month, all NYSE stocks on CRSP are sorted by firm size to determine the NYSE decile breakpoints for market capitalization. Then, we exclude all NYSE/AMEX/NASDAQ stocks with market capitalizations that would place them in the smallest NYSE size decile. We also exclude stocks whose price is less than $\$ 5$ per share.
} 


\section{Preliminary Evidence}

Given the number of potential control variables, i.e., other stock characteristics that may influence returns, the Fama-MacBeth cross-sectional regression approach may be the natural way to examine the predictive power of measures of tail risk. We turn to these regressions in Section 5; however, in order to get an initial feel for the data, we first look at univariate sorts on the basis of our three tail risk measures and the associated characteristics of the portfolios.

\subsection{Average Returns for Univariate Portfolio Sorts}

Table 1 presents the average monthly returns for the equal-weighted, decile portfolios that are formed by sorting the NYSE, AMEX, and NASDAQ stocks based on our three tail risk measures - H-TCR, LPM $\left(\mathrm{R}_{\mathrm{i}}\right)$, and $\beta_{\mathrm{LPM}}$. We also report the average across months of the median tail risk measure within each portfolio. The returns are reported for the sample period July 1963 to December 2009, while the measures of tail risk are computed over the preceding six months. Portfolio 1 (Low) contains stocks with the lowest tail risk and Portfolio 10 (High) includes stocks with the highest tail risk in the previous six months.

We turn first to our new hybrid measure of tail covariance risk. By construction, the average H-TCR of individual stocks in the univariate sort increases monotonically across the deciles, from -0.266 for Portfolio 1 to 0.124 for Portfolio 10. Since we are conditioning on states in which the individual stock return is less than the specified threshold, the stock specific term in equation (9) is always negative. Thus, a negative (positive) H-TCR indicates that the market term is positive (negative), on average, in these same states. Positive and large H-TCRs correspond to stocks whose low returns coincide with those of the market as a whole. In other words, they have substantial tail risk because a portfolio with significant weights in both the stock and the market will tend to have returns in the left tail due to the coincidence of tail events for both assets.

As shown in the first column, the average return of individual stocks is about $0.45 \%$ per month for the low H-TCR decile (Portfolio 1) and 1.22\% per month for the high H-TCR decile (Portfolio 10). The raw average return difference between decile 10 and 1 is $0.77 \%$ per month (9.2\% per annum) with a Newey-West (1987) t-statistic of 5.29. In other words, there is evidence that our hybrid measure of tail risk is priced in the cross-section consistent with the model in Section 2. However, there is also some evidence of non-monotonicity in the average portfolio 
returns, and we have not yet made an effort to control for other priced risks that may vary across these portfolios.

The results for the other two tail risk measures are in sharp contrast to those for H-TCR. When stocks are sorted on the LPM of their daily returns over six months, this measure of stockspecific tail risk is negatively associated with raw portfolio returns. That is, the average returns on stocks with high LPMs are lower than those with less risk, with a return difference of $-0.71 \%$ that is economically large in magnitude and statistically significant (with a t-statistic of -2.84). While this result is somewhat disappointing from the perspective of uncovering priced tail risk in our framework of under-diversified holdings, it is perhaps not totally surprising. As we analyze in more detail below, LPM is correlated with other measures of stock-specific risk, specifically volatility (Ang et al. (2006, 2009)) and extreme returns (Bali et al. (2011)), that have been shown to have a strong relation to returns in the cross-section. Thus, isolating the effect of stockspecific tail risk may be extremely difficult.

Finally, our measure of systematic tail risk, $\beta_{\mathrm{LPM}}$, is also negatively associated with portfolio returns in the cross-section in the sense that the returns on Portfolio 1 are larger than those on Portfolio 10. However, the difference is economically and statistically insignificant, and the portfolio returns are clearly non-monotonic. In light of the voluminous literature attempting, and in many cases failing, to find significant pricing of systematic risk measures in the crosssection, this result is not totally unexpected.

\subsection{Descriptive Statistics for Tail Risk Portfolios}

While the raw return differences between the high and low H-TCR deciles are economically and statistically significant, the pattern across deciles in raw returns is not quite monotonic. Moreover, stock-specific tail risk, as measured by LPM, appears to be negatively priced in raw returns. These patterns in the data could be the result of additional priced risk factors, and these factors might also influence the risk-adjusted return differences across portfolios. To highlight the firm characteristics and risk attributes of stocks in the portfolios of Table 1, Table 2 presents descriptive statistics for the stocks in the various deciles. Specifically, Panels A through C report the average across the months in the sample of the median values within each month of various characteristics for the stocks in each decile sorted by H-TCR, $\operatorname{LPM}\left(\mathrm{R}_{\mathrm{i}}\right)$, and $\beta_{\mathrm{LPM}}$, respectively. In each case, we report values for the three tail risk measures, the price (in dollars), the market 
beta, the log market capitalization (in millions of dollars), the book-to-market (BM) ratio, the return over the 6 months prior to portfolio formation (MOM), the return in the portfolio formation month (REV), a measure of illiquidity (scaled by $10^{5}$ ), the co-skewness, the idiosyncratic volatility, and the maximum daily return in the portfolio formation month (MAX). Definitions of these variables are given in the Appendix.

Table 2, Panel A reports the characteristics for the portfolios sorted on H-TCR. ${ }^{9}$ Our hybrid measure of tail risk is positively related to systematic tail risk, as measured by $\beta_{\mathrm{LPM}}$, but non-monotonically related to stock-specific tail risk, as measured by $\operatorname{LPM}\left(\mathrm{R}_{\mathrm{i}}\right)$. This latter result is a manifestation of the fact that many tail events for individual stocks are idiosyncratic. Stocks with large idiosyncratic negative returns have high values of LPM but low values of H-TCR, whereas stocks with large systematic negative returns have high values of both LPM and HTCR.

Interestingly, stocks with high H-TCR are larger, higher priced, and more liquid stocks, on average. The intuition behind this result is that while smaller stocks tend to have more extreme negative returns, these tail events are also more likely to be idiosyncratic. Thus, in the context of our hypothesized portfolios of concentrated positions in individual stocks plus additional wealth in a well-diversified fund, it is the larger stocks that generate more portfolio tail risk after controlling for the stock-specific component. This size and liquidity discrepancy suggests that the raw return difference will hold up to risk adjustment on these dimensions. Large stocks and liquid stocks, on average, have low returns, whereas stocks with low systematic risk in the left tail (low H-TCR) are small, illiquid stocks that should have high returns, all else equal. Apparently, in the raw returns, the effect of hybrid tail risk dominates the effect of size or liquidity on future returns.

Market beta also increases as H-TCR increases, implying that stocks with high hybrid covariance risk in the lower tail of the stock return distribution are more exposed to market risk. Of course, this systematic risk likely does not explain the raw return differences across portfolios in Table 1 since market beta is weakly priced, at best, in the cross-section of returns.

In contrast, it will be important to control for momentum when risk-adjusting returns. Stocks with high H-TCR (low H-TCR) are generally past winners (losers) over an horizon of 6

\footnotetext{
${ }^{9}$ The average across months of the median H-TCR for each portfolio differs slightly from that reported in Table 1 because the sample is slightly smaller due to the data requirements necessary to calculate some of the other variables.
} 
months, and thus H-TCR-sorted portfolios should exhibit the well-documented intermediate-term momentum phenomenon. On the other hand, both median book-to-market ratios (BM) and average returns in the portfolio formation month (REV) are similar across the H-TCR portfolios, indicating no association between H-TCR and the value premium or short-term reversals.

COSKEW (Harvey and Siddique (2000)) measures the direction and strength of the relation between individual stock returns and squared market returns, implying that stocks with high co-skewness have high (low) returns when market volatility is high (low). A preference for positive skewness suggests a negative price for co-skewness risk. Panel A indicates that stocks with high H-TCR also have high co-skewness, indicating that this phenomenon is unlikely to be an explanation for our results.

The final 2 columns of Panel A examine two properties of the stock return distributionidiosyncratic volatility and the prevalence of extreme positive returns - both of which have been linked to expected returns in the literature. Stocks with high H-TCR seem to have somewhat lower idiosyncratic volatility and lower maximum daily returns in the portfolio formation month. Interestingly, the patterns across portfolios in both IVOL and MAX do superficially resemble those in the raw returns in Table 1.

Panel B reports the same characteristics as Panel A for portfolios sorted on $\operatorname{LPM}\left(\mathrm{R}_{\mathrm{i}}\right)$ rather than H-TCR. These characteristics may suggest a potential explanation for the anomalous negative relation between raw returns and stock-specific tail risk in Table 1. Clearly, such an explanation cannot rely on market beta, size, or illiquidity, since these effects go in the opposite direction to the raw returns across the deciles. More likely candidates are the stock-specific return distribution measures, idiosyncratic volatility (IVOL) and extreme positive returns (MAX). Both of these variables have a strong negative relation to returns in the cross-section and increase monotonically across the $\mathrm{LPM}\left(\mathrm{R}_{\mathrm{i}}\right)$-sorted portfolios. This association between LPM, idiosyncratic volatility, and extreme returns is both expected and probably difficult to resolve empirically.

In Panel C, we report the characteristics of portfolios sorted on our final tail risk measure, systematic tail risk as measured by $\beta_{\text {LPM. }}$. There is little or nothing surprising in the results. Tail beta is positively associated with market beta, co-skewness, idiosyncratic volatility, and extreme positive returns. 
To further understand the interaction of tail risk with firm characteristics and risk attributes, we compute the firm-level cross-sectional correlations of all the variables for each month from July 1963 to December 2009. Table 2, Panel D reports the time-series averages of these cross-sectional correlations. Confirming our earlier findings at the portfolio level, hybrid tail risk, H-TCR, is positively correlated with market beta, size, momentum, and co-skewness and negatively correlated with illiquidity, idiosyncratic volatility, and MAX. The correlations of H-TCR with book-to-market and reversals are very small, with magnitudes less than 0.03. Stockspecific tail risk, $\operatorname{LPM}\left(\mathrm{R}_{\mathrm{i}}\right)$, is strongly positively correlated with both idiosyncratic volatility and MAX, as is systematic tail risk, $\beta_{\text {LPM }}$.

\section{Firm-Level Cross-Sectional Regressions}

The univariate-sort portfolio results in Table 1 are certainly consistent with H-TCR being priced in the cross-section, but Table 2 identifies a number of risk factors that may play a role in the results. Therefore, we now examine the cross-sectional relation between H-TCR and expected returns at the firm level using the Fama and MacBeth (1973) methodology. Specifically, we run the following multivariate specification and nested versions thereof:

$$
R_{i, t+1}=\lambda_{0, t}+\lambda_{1, t} X_{i, t}+\lambda_{2, t} B E T A_{i, t}+\lambda_{3, t} \operatorname{SIZE}_{i, t}+\lambda_{4, t} B M_{i, t}+\lambda_{5, t} \operatorname{MOM}_{i, t}+\lambda_{6, t} Z_{i, t}+\varepsilon_{i, t+1}
$$

where $X_{i, t}$ is one of the three tail risk measures- $\mathrm{H}$-TCR, LPM $\left(\mathrm{R}_{\mathrm{i}}\right)$, and $\beta_{\mathrm{LPM}}$; BETA, SIZE, BM, and MOM are the four Fama-French-Carhart factors; and $Z_{i, t}$ represents the possible inclusion of other control variables.

Table 3, Panel A reports the time series averages of the slope coefficients over the sample period July 1963-December 2009 (558 monthly observations) from the univariate regressions of one-month ahead stock returns on our three tail risk measures and multivariate regressions on each tail risk measure with the four Fama-French-Carhart factors. The average slopes provide standard Fama-MacBeth tests for determining which explanatory variables on average have nonzero premiums, and the Newey-West adjusted t-statistics are given in parentheses.

Not surprisingly, the univariate cross-sectional regression results are consistent with the raw return differences across portfolios from the univariate portfolio sorts in Table 1. The average slope on H-TCR is 2.88 with a t-statistic of 4.77 . Given a difference in median H-TCR of approximately 0.39 between the high and low H-TCR deciles, this coefficient estimate translates into a monthly return difference of $1.12 \%$, about $50 \%$ higher than the economic effect 
seen in Table 1. For both $\operatorname{LPM}\left(\mathrm{R}_{\mathrm{i}}\right)$ and $\beta_{\mathrm{LPM}}$, the coefficients are economically small and statistically insignificant.

In the multivariate regressions, the coefficients on the Fama-French-Carhart factors are also as expected. The average slope on BETA is negative and statistically insignificant, which is consistent with prior empirical evidence. The average slope on SIZE is negative, but only sporadically significant at the 5\% level. This lack of statistical significance is due to the exclusion of small and low-priced stocks from our sample, the sector of the market in which the traditional size effect is concentrated. There is a significantly positive value premium as the average slope on BM is positive and significant with t-statistics between 2.2 and 3.0. Finally, stocks exhibit strong intermediate-term momentum, proxied by the cumulative return over the 6 months prior to the return prediction month. Since momentum is often measured over a period longer than 6 months, we also re-run the 4-factor multivariate cross-sectional regressions, replacing the 6-month momentum variable (MOM) with momentum defined as the cumulative return over the previous 12 months starting 2 months ago (MOM12). As shown in Table 3, the average slopes on both momentum variables are positive and highly significant with t-statistics ranging from 4.1 to 5.1 .

Of greater interest are the average slope coefficients on the tail risk measures. The predictive power of H-TCR remains after controlling for the Fama-French-Carhart factors, including alternative definitions of momentum. In the multivariate regressions, the coefficient on H-TCR is above 2 with t-statistics greater than 5. The implied economic magnitude of the effect is slightly lower than in the univariate regression, but at a difference of approximately 85 to 89 basis points per month between median stocks in the high and low H-TCR deciles, it is still large. The slight attenuation is due partly to the inclusion of the momentum factor, with which H-TCR is positively correlated. The coefficient in a similar regression with only the three FamaFrench factors is larger.

Controlling for the additional risk factors has a large effect on the $\operatorname{LPM}\left(\mathrm{R}_{\mathrm{i}}\right)$ coefficient. The magnitude more than doubles to -0.2 , and it becomes statistically significant at all standard levels, with a t-statistic exceeding 4 in magnitude. However, the sign on the coefficient is inconsistent with $\operatorname{LPM}\left(\mathrm{R}_{\mathrm{i}}\right)$ being a measure of priced tail risk—-stocks with high stock-specific tail risk apparently have lower expected returns. This anomalous result strongly suggests that this variable is proxying for an omitted factor. 
For systematic tail risk, the inclusion of the additional factors has little effect. The coefficient remains small in magnitude and of the wrong sign, albeit statistically insignificant.

Table 3, Panel B reports results for multivariate regressions that include each of the additional control variables from Table 2 in turn. The coefficients on these variables are generally in line with the existing literature. The average slope on REV is negative and highly significant, implying that stocks exhibit strong short-term reversals. There is evidence of statistically significant coefficients on illiquidity and co-skewness, but in both cases the sign is the opposite of that implied by the theory. For illiquidity, this result is likely due to the exclusion of small and low-priced stocks from the sample. Finally, consistent with the findings of Ang et al. (2006) and Bali, Cakici, and Whitelaw (2011), the results indicate a negative and significant relation between expected returns and the IVOL and MAX variables.

Again, it is the tail risk variables that are of primary interest. For H-TCR, the inclusion of controls for return reversals, illiquidity, or co-skewness has little effect. However, both IVOL and MAX reduce the coefficient on H-TCR by approximately 50\%. The effects of these control variables are extremely strong in the data with a sign opposite to that of H-TCR, and they are negatively correlated with H-TCR. Nevertheless, H-TCR remains economically and statistically significant in all the specifications.

Interestingly, the pattern of coefficients across regressions is similar for $\operatorname{LPM}\left(\mathrm{R}_{\mathrm{i}}\right)$. Reversals, illiquidity and co-skewness have little effect, but the inclusion of either IVOL or MAX reduces the coefficient by about $50 \%$. In this case, the sign of the coefficient on $\operatorname{LPM}\left(\mathrm{R}_{\mathrm{i}}\right)$ and the control variables (IVOL, MAX) is the same, but the variables are positively correlated. Regardless of the specification, the anomalous sign on stock-specific tail risk is preserved.

For systematic tail risk, it is the control for co-skewness that has the largest effect on the results. When this control variable is added to the regression, the magnitude of the coefficient on $\beta_{\mathrm{LPM}}$ increases and becomes marginally significant. However, given that the signs of the coefficients on both systematic tail risk and co-skewness are the opposite of those implied by theory, this particular result should be interpreted with caution.

The tail risk measures in Tables 1, 2, and 3 are constructed using the $10 \%$ tails of the relevant return distributions over the preceding six months. The choice of $10 \%$ and six months is somewhat arbitrary, although it intuitively provides a reasonable tradeoff between a sufficient number of observations to limit estimation error and the desire to get a measure of tail risk rather 
than more general downside risk. We now investigate the predictive power of alternative measures of $\mathrm{H}-\mathrm{TCR}, \mathrm{LPM}\left(\mathrm{R}_{\mathrm{i}}\right)$, and $\beta_{\mathrm{LPM}}$ estimated using different tails of the daily return distribution over the preceding year (instead of six months). ${ }^{10}$ Moreover, there is the more fundamental issue of the nature of investor preferences or the asymmetry properties of joint return distributions that generate a role for tail risk. To partially address both these issues, we rerun the multivariate cross-sectional regressions above with the three annual tail risk measures and the Fama-French-Carhart risk factors, varying the fraction of the lower half of the return distribution over which we calculate tail risk. The results are reported in Table 4, which contains the average slope coefficients and associated t-statistics for the tail risk measures but omits the coefficients for the other risk factors in the interest of brevity.

For H-TCR, the pattern in coefficients as the definition of the tail of the distribution changes is consistent with the theoretical intuition. The coefficient and statistical significance peak when H-TCR is calculated using the $5 \%$ and $10 \%$ tails, respectively. When H-TCR is measured over the full lower half of the distribution, i.e., when it becomes a downside risk rather than tail risk measure, the magnitude of the coefficient is small, the sign is reversed, and it is statistically insignificant.

The pattern for stock-specific risk, as measured by $\operatorname{LPM}\left(\mathrm{R}_{\mathrm{i}}\right)$, is markedly different. The coefficient remains large in magnitude, and its statistical significance is preserved for all tail values from $5 \%$ to $50 \%$. This evidence confirms the conclusion above that the significance of $\operatorname{LPM}\left(\mathrm{R}_{\mathrm{i}}\right)$ is not due to its ability to pick up tail risk at all. Instead, it is proxying for the more general features of the return distribution associated with idiosyncratic volatility and extreme returns (MAX). One should not conclude from these results that stock-specific tail risk is unpriced, rather that disentangling the pricing of this risk from the pricing of related distributional risks is an extremely challenging empirical exercise, which is beyond the scope of this paper.

Finally, the negative but statistically insignificant coefficients for systematic tail risk are evident across the various definitions of the tail. Like many existing papers, we are unable to document that systematic risk, in our case tail risk, is priced in the cross-section. However, the results for the 50\% tail appear to contradict those of Ang, Chen, and Xing (2006), who report

\footnotetext{
${ }^{10}$ The choice of a longer period over which to calculate tail risk allows us to go deeper into the tail, i.e., to the $5 \%$ level, while still having a sufficient number of daily observations.
} 
significant compensation in the form of higher expected returns for those stocks with higher systematic downside risk. Our sample period and methodology differ somewhat, but the primary reason for the discrepancy appears to be sample selection. Ang, Chen, and Xing (2006) restrict their sample to NYSE stocks and eliminate the $20 \%$ of these stocks with the highest volatility, whereas we use the broader NYSE/AMEX/NASDAQ sample and eliminate small and low priced stocks due to concerns about liquidity and the associated microstructure issues.

The clear conclusion from our empirical analysis is that cross-sectional regressions provide strong evidence for an economically and statistically significant positive relation between hybrid tail covariance risk and future returns, consistent with models that suggest that risk in the left tail of portfolio returns is priced and that prices are influenced by investors with concentrated holdings in individual securities and positions in more diversified portfolios. The evidence for both stock-specific and systematic tail risk measures is more mixed. In the former case, the results strongly suggest an inability to distinguish the desired effect from other effects associated with the stock-specific distribution of returns. In the latter case, the effect may be too small to detect with any degree of precision given measurement issues.

\section{Further Evidence on Hybrid Tail Covariance Risk}

Given the evidence above of statistically and economically significant pricing of hybrid tail covariance risk in the cross-section of stocks, we now proceed to examine this phenomenon in more detail, examining first the time series persistence of H-TCR and then turning to alternative measures of tail covariance risk and tail beta.

\subsection{Persistence}

As is appropriate for a study of cross-sectional expected returns, we calculate tail risk over a specific time window (six months in much of the previous analyses) and examine returns over the subsequent month. However, in a rational setting, investors should only care about historical hybrid tail covariance risk to the extent that it predicts future risk. Alternatively, if one views the phenomenon we document as mispricing, then the portfolio turnover associated with a strategy that exploits this mispricing is of interest.

To examine this issue we compute the transition matrix for decile portfolios formed by sorting on H-TCR. Table 5, Panel A reports the average of the month-to-month transition 
matrices for the stocks in these portfolios, i.e., the average probability (in percent) that a stock in decile $i$ (as given by the rows of the matrix) in one month will be in decile $j$ (as given by the columns of the matrix) in the subsequent month. Because we calculate H-TCR over six months, there is a 5-month overlap between H-TCR calculated in two adjacent months, which generates persistence in portfolio membership by construction. Thus, the diagonals of the transition matrix reflect both the overlap and the persistence in tail risk. For the extreme deciles, portfolios 1 (Low H-TCR) and 10 (High H-TCR), close to $70 \%$ of the stocks remain in the extreme decile in the following month.

To eliminate the persistence caused by the overlap, Panel B reports the average of the 6month lag transition matrices for the stocks in these portfolios, i.e., the average probability (in percent) that a stock in decile $i$ (as given by the rows of the matrix) in one month will be in decile $j$ (as given by the columns of the matrix) 6 months later. Despite the high hurdle presented by the six months lag, this transition matrix also shows substantial evidence of persistence. Approximately $20 \%$ of stocks in the extreme portfolios are still in the same portfolios six months later, and approximately $35 \%-40 \%$ of the stocks are in the top or bottom two deciles. In other words, H-TCR predicts both returns and future tail risk in the cross-section.

\subsection{Alternative Measures of Hybrid Tail Covariance Risk}

As presented in equation (9), we have so far used six months of daily returns and the $10 \%$ lower tail to estimate hybrid tail covariance risk (H-TCR) and predict returns in the subsequent month. In order to get additional insight into the relation between tail risk and returns, we generate alternative measures of tail covariance risk and test their predictive power for the cross-section of expected returns.

Specifically, alternative measures of H-TCR are computed based on the daily returns from the (i) $5 \%$ lower tail of the daily return distribution over the past 12 months; (ii) $10 \%$ lower tail of the daily return distribution over the past 12 months; (iii) 10\% lower tail of the daily return distribution over the past 6 months; (iv) 20\% lower tail of the daily return distribution over the past 6 months; and (v) $20 \%$ lower tail of the daily return distribution over the past 3 months. As the calculation window is reduced, we increase the tail size in order to keep the number of daily observations used in computing H-TCR sufficiently large. 
Table 6, Panel A shows that, for all measures of H-TCR, the average raw return increases when moving from the low H-TCR to the high H-TCR portfolio. The average raw return differences are in the range of $0.48 \%$ to $0.77 \%$ per month with Newey-West t-statistics ranging from 2.76 to 5.29. The results, both in terms of the magnitude of the return difference and its statistical significance, seem to improve as the window length is reduced, i.e., we use more recent information, and as we focus on a smaller fraction of the more extreme tail observations.

In addition to the average raw returns, Panel A also presents the magnitude and statistical significance of the difference in intercepts from the regression of the equal-weighted H-TCR portfolio returns on a constant, the excess market return, a size factor (SMB), a book-to-market factor (HML), following Fama and French (1993), and Carhart's (1997) momentum (MOM) factor. ${ }^{11}$ The four-factor alpha differences between the low H-TCR and high H-TCR portfolios are in the range of $0.51 \%$ to $0.69 \%$ per month and are highly significant, with the t-statistics ranging from 3.29 to $5.24 .^{12}$

These results indicate an economically and statistically significant, positive relation between hybrid tail covariance risk and the cross-section of expected returns. An investment strategy that goes long stocks in the highest H-TCR decile and shorts stocks in the lowest H-TCR decile produces average raw and risk-adjusted returns in the range of $5.8 \%$ to $9.2 \%$ on an annualized basis.

\subsection{Hybrid Tail Beta}

We have so far measured hybrid risk in the lower tail of the return distribution using tail covariance risk. In this section, we construct an alternative measure called hybrid tail beta defined as the ratio of hybrid tail covariance risk to the lower partial moment of the market portfolio:

$$
\text { Hybrid Tail Beta }=\frac{H-T C R}{\operatorname{LPM}\left(R_{m}\right)}=\frac{\sum_{R_{i}<h_{i}}\left(R_{i}-h_{i}\right)\left(R_{m}-h_{m}\right)}{\sum_{R_{i}<h_{i}}\left(R_{m}-h_{m}\right)^{2}}
$$

\footnotetext{
${ }^{11}$ SMB (small minus big), HML (high minus low), and MOM (winner minus loser) are described in and obtained from Kenneth French's data library: http://mba.tuck.dartmouth.edu/pages/faculty/ken.french/.

${ }^{12}$ The three-factor Fama-French alpha differences are even larger and more statistically significant than those that control for momentum; however, we report only the latter for the sake of brevity.
} 
This tail risk measure is the same as the measure of $\beta_{i, L P M}$ in equation (6), except that the moments in the numerator and denominator are conditioned on states in which the return on the individual stock is in the tail of its distribution rather than on states in which the market return is in the tail. Relative to tail covariance risk, tail beta has the advantage of being normalized to a more standard scale.

We generate alternative measures of tail beta computed based on daily returns from the (i) $5 \%$ lower tail of the daily return distribution over the past 12 months; (ii) $10 \%$ lower tail of the daily return distribution over the past 12 months; (iii) $10 \%$ lower tail of the daily return distribution over the past 6 months; (iv) $20 \%$ lower tail of the daily return distribution over the past 6 months; and (v) 20\% lower tail of the daily return distribution over the past 3 months.

Table 6, Panel B shows that for all measures of hybrid tail beta the average raw return increases when moving from the low tail beta to the high tail beta portfolio. The average raw return differences are in the range of $0.52 \%$ to $0.78 \%$ per month with Newey-West t-statistics ranging from 3.20 to 5.67, comparable but slightly stronger than those reported in Panel A for hybrid tail covariance risk. The Fama-French-Carhart four-factor alpha differences between the low tail beta and high tail beta portfolios are in the range of $0.44 \%$ to $0.64 \%$ per month and are also highly significant, with t-statistics ranging from 2.70 to $4.44 .^{13}$ These results indicate an economically and statistically significant, positive relation between expected returns and alternative measures of tail beta. The annual average raw and risk-adjusted returns of stocks in the highest tail beta decile are $5.2 \%$ to $9.4 \%$ higher than the annual average returns of stocks in the lowest tail beta decile.

As with H-TCR, hybrid tail betas measured over shorter periods and deeper in the tail appear to have more economically and statistically significant predictive power. Of course, as the window length decreases, it is necessary to increase the fraction of the distribution used to measure tail risk in order to ensure a sufficient number of observations to avoid severe measurement error issues.

\section{Robustness Checks}

While cross-sectional regressions are arguably the best way to deal with large sets of potential risk factors, in this section we provide two alternative ways of dealing with the potential

\footnotetext{
${ }^{13}$ As before, Fama-French three-factor alpha differences are uniformly larger and more statistically significant.
} 
interaction of tail covariance risk with firm size, book-to-market, past returns, liquidity, coskewness, idiosyncratic volatility, and MAX. Specifically, we test whether the positive relation between H-TCR and the cross-section of expected returns still holds once we control for these additional factors using bivariate sorts of portfolios and characteristic-matched benchmark portfolios. We also provide results from a screening mechanism to rule out the possibility that extreme stocks of various types are driving our results.

\subsection{Dependent Sorts}

For the dependent bivariate sorts our general methodology is to first form deciles on the control variable, then, within each of these deciles, to form deciles on the basis of H-TCR. We then average the H-TCR deciles across the control variable deciles to form portfolios with similar levels of the control variable but different levels of H-TCR. For example, we control for size by first forming decile portfolios based on market capitalization. Then, within each size decile, we sort stocks into decile portfolios based on tail covariance risk (H-TCR) so that decile 1 (decile 10) contains stocks with the lowest (highest) H-TCR. The first column in Table 7 averages returns across the 10 size deciles to produce decile portfolios with dispersion in H-TCR, but which contain firms of all sizes. This procedure creates a set of H-TCR portfolios with nearly identical levels of firm size, and thus these H-TCR portfolios control for differences in size. After controlling for size, the average return increases from $0.55 \%$ per month to $1.28 \%$ per month when moving from the low H-TCR to the high H-TCR portfolios, yielding an average return difference of $0.73 \%$ per month, with a Newey-West t-statistic of 5.62. The 10-1 difference in four-factor alphas is $0.53 \%$ per month, and it is also highly statistically significant. ${ }^{14}$ Thus, market capitalization does not explain the return difference between high and low H-TCR stocks.

We form similar bivariate decile portfolios based on the dependent sorts of H-TCR and book-to-market, momentum, short-term reversals, liquidity, co-skewness, idiosyncratic volatility, and MAX. Table 7 shows that after controlling for these variables, the average return differences between the low H-TCR and high H-TCR portfolios are in the range of $0.35 \%$ to $0.73 \%$ per month, and the differences in four-factor alphas vary over the same range. These average raw and risk-adjusted return differences are both economically and statistically significant.

\footnotetext{
${ }^{14}$ As before, for the sake of brevity we do not report the differences in three-factor alphas, but they are uniformly greater in magnitude than the corresponding differences in four-factor alphas.
} 
Of some additional interest, the bivariate sort on MAX eliminates much of the nonmonotonicity associated with the univariate sorts in Tables 1 and 6, illustrating the potential interaction between different risk factors. Overall, the results in Table 7 indicate that the wellknown cross-sectional effects such as size, book-to-market, past return characteristics, liquidity, co-skewness, idiosyncratic volatility, and MAX cannot explain the high (low) returns to high (low) H-TCR stocks.

\subsection{Characteristic-Matched Portfolios}

In Table 8, we further examine whether the significantly positive relation between tail covariance risk and expected returns is due to size, book-to-market, momentum, reversals, liquidity, coskewness, idiosyncratic volatility, or MAX effects. In the column labeled "Size/BM Adjusted," we report the average returns in excess of the size and book-to-market matched benchmark portfolios similar to the procedure in Daniel and Titman (1997). In the next six columns, we include additional controls for momentum, short-term reversals, illiquidity, co-skewness, idiosyncratic volatility, and MAX. For each additional control, we first perform a decile sort based on the characteristic and then on hybrid tail covariance risk (H-TCR). Finally, we average the H-TCR deciles across the characteristic deciles and report size and book-to-market matched returns within each H-TCR decile. Portfolio 1 (10) is the portfolio of stocks with the lowest (highest) tail covariance risk.

As presented in the first column of Table 8, after controlling for size and book-to-market simultaneously, the average return difference between the low H-TCR and high H-TCR deciles is about $0.59 \%$ per month with a Newey-West t-statistic of 5.35 . The last six columns of Table 8 clearly show that the spreads in size and book-to-market adjusted returns between H-TCR deciles 10 and 1 remain positive and significant after controlling for momentum, short-term reversals, liquidity, co-skewness, idiosyncratic volatility, and MAX. The average return difference between the low H-TCR and high H-TCR deciles is in the range of $0.35 \%$ to $0.60 \%$ per month with t-statistics ranging from 3.53 to 5.83 . Thus, the predictive power of hybrid tail covariance risk is not due to the aforementioned cross-sectional effects. 


\subsection{Further Screening for Liquidity, Volatility, Momentum, and Reversals}

So far, we have used bivariate sorts, characteristic-matched portfolios, and cross-sectional regressions to deal with the potential interaction of the tail covariance risk with firm size, bookto-market, momentum, short-term reversals, liquidity, co-skewness, idiosyncratic volatility, and MAX. An alternative way of demonstrating the robustness of our results is to exclude small, low-priced, illiquid, highly volatile, and extreme short-term and intermediate-term winner and loser stocks in the formation of H-TCR portfolios. As discussed earlier, we use a sample that excludes NYSE/AMEX/NASDAQ stocks that are in the smallest NYSE size decile and stocks trading below $\$ 5$ per share. Our further screening process for liquidity, volatility, intermediateterm return continuation, and short-term return reversals is as follows:

(1) Liquidity: To screen for liquidity, all NYSE stocks are sorted each month by the ratio of absolute stock return to dollar volume to determine the NYSE decile breakpoints. Then, we exclude all stocks that fall in the smallest NYSE liquidity decile (or the largest NYSE illiquidity decile).

(2) Volatility: To screen for total volatility, all NYSE stocks are sorted each month by their idiosyncratic volatility to determine the NYSE decile breakpoints for the volatility measure. Then, we exclude all stocks that fall in the highest NYSE idiosyncratic volatility decile.

(3) Winners: To screen for past 6-month winners, all NYSE stocks are sorted each month by their 6-month cumulative returns from month t-7 to t-2 to determine the NYSE decile breakpoints. Then, we exclude the winner stocks that fall in the highest NYSE return decile. We follow the same procedure for past 1-month winners.

(4) Losers: We screen for past 6-month and 1-month losers using a procedure analogous to that for winners above.

(5) Momentum: To screen for momentum, we eliminate both the 6-month winners and 6-month losers as described above.

(6) Short-term reversals: As indicated by Jegadeesh (1990) and Lehmann (1990), returns in month $\mathrm{t}-1$ are subject to short-term reversals in month $\mathrm{t}$. Hence, to screen for short-term reversals, we estimate the tail covariance risk using daily returns from month $t-12$ to month $t-2$, skipping returns in month $\mathrm{t}-1$.

After further screening for liquidity, volatility, momentum, and short-term reversals, the equal-weighted decile portfolios are formed every month from January 1963 to December 2009 
by sorting the NYSE/AMEX/NASDAQ stocks based on the tail covariance risk calculated using the $10 \%$ lower tail of the daily stock return distribution over the past 6 months. Portfolio 1 (10) is the portfolio of stocks with the lowest (highest) tail covariance risk.

Table 9 reports the average returns in monthly percentage terms on H-TCR portfolios. The average raw return difference between deciles 10 and 1 is in the range of $0.36 \%$ to $0.73 \%$ per month with Newey-West t-statistics ranging from 2.59 to 5.03. The 10-1 differences in fourfactor alphas are also positive and economically and statistically significant. Based on the average raw and risk-adjusted return differences, we find a positive and significant relation between hybrid tail covariance risk and expected returns after screening for small, illiquid, highly volatile, and extreme winner and loser stocks.

\section{Conclusion}

Motivated by under-diversification on the part of individual investors and further evidence that these investors hold some of their wealth in well-diversified funds in addition to their concentrated holdings of equities, we construct a measure of tail risk that depends on the covariance between individual stock returns and the market return conditional on the returns on the stock being in the lower tail of its distribution. This measure, which we denote hybrid tail covariance risk (H-TCR), shows significant and robust ability to predict future returns. Annualized risk-adjusted return differences between high and low H-TCR stocks are 6-9\%, depending on the precise specification and methodology.

These results contrast starkly with those from either purely stock-specific or purely systematic measures of tail risk. In the former case, this risk appears to be negatively priced, an anomalous result that we attribute to severe co-linearity between stock-specific tail risk measures and other distributional characteristics of stock returns such as volatility and the prevalence of extreme returns, both of which have been shown to be strongly correlated with future returns. This issue clearly deserves further study. In the latter case, the estimated price of risk is negative, small in magnitude, and statistically insignificant, adding to the wealth of existing failures to detect the pricing of systematic risk in the cross-section of stocks. 


\section{Appendix: Variable Definitions}

Market Beta: To estimate the market beta of an individual stock, we assume a single factor return generating process:

$$
R_{i, d}=\alpha_{i}+\beta_{i} R_{m, d}+\varepsilon_{i, d}
$$

where $R_{i, d}$ is the return on stock $i$ on day $d$ and $R_{m, d}$ is the market return on day $d$. We estimate equation (14) for each stock using daily returns over the past one year. The estimated slope coefficient $\hat{\beta}_{i}=\operatorname{cov}\left(R_{i, d}, R_{m, d}\right) / \operatorname{var}\left(R_{m, d}\right)$ is the market beta of stock $i$.

Size: Following the existing literature, firm size is measured as the natural logarithm of the market value of equity (a stock's price times shares outstanding) for each stock.

Book-to-market: Following Fama and French (1992), we compute a firm's book-to-market ratio using its market equity at the end of December of year $t-1$ and the book value of common equity plus balance-sheet deferred taxes for the firm's latest fiscal year ending in calendar year $t-1{ }^{15}$

Momentum: Following Jegadeesh and Titman (1993), the momentum variable for each stock in month $t$ is defined as the cumulative return on the stock over the previous 7 months but skipping the most recent month, i.e., the 6-month cumulative return from month $t-7$ to month $t-2$. We also use an alternative definition of momentum defined as the cumulative return on the stock over the previous 12 months again skipping the most recent month, i.e., the 11-month cumulative return from month $t-12$ to month $t-2$.

Short-term Reversals: Following Jegadeesh (1990) and Lehmann (1990), the reversal variable for each stock in month $t$ is defined as the return on the stock over the previous month, i.e., the return in month $t-1$.

Liquidity: Following Amihud (2002), we measure stock illiquidity as the ratio of the absolute return on a stock to its dollar trading volume: $I L L I Q_{i, t}=\left|R_{i, t}\right| / V O L D_{i, t}$, where $R_{i, t}$ is the return on stock $i$ in month $t$, and $V O L D_{i, t}$ is the respective monthly trading volume in dollars.

Co-skewness: Following Harvey and Siddique (2000), co-skewness is defined as:

$$
\text { Coskew }_{i}=\frac{E\left[\left(R_{i}-\mu_{i}\right)\left(R_{m}-\mu_{m}\right)^{2}\right]}{\sqrt{\operatorname{var}\left(R_{i}\right)} \operatorname{var}\left(R_{m}\right)},
$$

\footnotetext{
${ }^{15}$ To avoid giving extreme observations heavy weight in our analysis, following Fama and French (1992), the smallest and largest $0.5 \%$ of the observations on book-to-market ratio are set equal to the next largest and smallest values of the ratio (the 0.005 and 0.995 fractiles).
} 
where $R_{i}$ is the daily return on stock $i$ over the past one year, $R_{m}$ is daily market return over the past one year, and $\mu_{i}$ and $\mu_{m}$ are the average daily returns on $R_{i}$ and $R_{m}$, respectively. $\operatorname{var}\left(R_{i}\right)$ and $\operatorname{var}\left(R_{m}\right)$ are the variance of daily returns on $R_{i}$ and $R_{m}$, respectively.

Idiosyncratic Volatility: Following Ang et al. (2006), we estimate the monthly idiosyncratic volatility of an individual stock using the three-factor Fama-French (1993) model:

$$
R_{i, d}-r_{f, d}=\alpha_{i}+\beta_{i}\left(R_{m, d}-r_{f, d}\right)+\gamma_{i} S M B_{d}+\delta_{i} H M L_{d}+\varepsilon_{i, d}
$$

where $S M B_{d}$ and $H M L_{d}$ are daily returns on the size and book-to-market factors of Fama and French (1993), and $\varepsilon_{i, d}$ is the idiosyncratic return on day $d$. Following Ang et al. (2006), the idiosyncratic volatility of stock $i$ in month $t$ is defined as the standard deviation of daily residuals in month $t: I V O L_{i, t}=\sqrt{\operatorname{var}\left(\varepsilon_{i, d}\right)}$.

Maximum Daily Return: Following Bali, Cakici, and Whitelaw (2011), MAX is defined as the maximum daily return within a month:

$$
M A X_{i, t}=\max \left(R_{i, d}\right) \quad d=1, \ldots, D_{t},
$$

where $R_{i, d}$ is the return on stock $i$ on day $d$ and $D_{t}$ is the number of trading days in month $t$. 


\section{References}

Amihud, Y., 2002, "Illiquidity and Stock Returns: Cross-Section and Time-Series Effects," Journal of Financial Markets, 5, 31-56.

Ang, A., J. Chen, and Y. Xing, 2006, “Downside Risk," Review of Financial Studies, 19, 11911239.

Ang, A., R. J. Hodrick, Y. Xing, and X. Zhang, 2006, "The Cross-Section of Volatility and Expected Returns," Journal of Finance, 61, 259-299.

Ang, A., R. J. Hodrick, Y. Xing, and X. Zhang, 2009, "High Idiosyncratic Volatility and Low Returns: International and Further U.S. Evidence," Journal of Financial Economics, 91, 1-23.

Bali, T. G., N. Cakici, and R. F. Whitelaw, 2011, "Maxing Out: Stocks as Lotteries and the Cross- Section of Expected Returns," Journal of Financial Economics, 99, 427-446.

Barber, B., and T. Odean, 2001, "Boys Will Be Boys: Gender, Overconfidence, and Common Stock Investment," Quarterly Journal of Economics, 116, 261-292.

Barro, R. J., 2006, "Rare Disasters and Asset Markets in the Twentieth Century," Quarterly Journal of Economics, 121, 823-866.

Bawa, V. S., 1975, “Optimal Rules for Ordering Uncertain Prospects,” Journal of Financial Economics, 2, 95-121.

Bawa, V. S., and E. B., Lindenberg, 1977, "Capital Market Equilibrium in a Mean-Lower Partial Moment Framework," Journal of Financial Economics, 5, 189-200.

Blume, M. E., J. Crockett, and I. Friend, 1974, "Stockholders in the United States: Characteristics and Trends," Survey of Current Business, 54, 16-40.

Blume, M. E., and I. Friend, 1975, "The Asset Structure of Individual Portfolios and some Implications for Utility Functions," Journal of Finance, 30, 585-603.

Carhart, M. M., 1997, “On Persistence in Mutual Fund Performance,” Journal of Finance, 52, 57-82.

Daniel, K., and S. Titman, 1997, "Evidence on the Characteristics of Cross-Sectional Variation in Stock Returns," Journal of Finance, 52, 1-33.

Dorn, D., and G. Huberman, 2005, "Talk and Action: What Individual Investors Say and What They Do," Review of Finance, 9, 437-481.

Dorn, D., and G. Huberman, 2010, "Preferred Risk Habitat of Individual Investors," Journal of Financial Economics, 97, 155-173. 
Fama, E. F., and K. French, 1992, "Cross-Section of Expected Stock Returns," Journal of Finance, 47, 427-465.

Fama, E. F., and K. French, 1993, "Common Risk Factors in the Returns on Stocks and Bonds," Journal of Financial Economics, 33, 3-56.

Fama, E. F., and J. D. MacBeth, 1973, "Risk and Return: Some Empirical Tests," Journal of Political Economy, 81, 607-636.

Goetzmann, W. N., and A. Kumar, 2008, "Equity Portfolio Diversification," Review of Finance, $12,433-463$.

Harlow, W., and R. Rao, 1989, "Asset Pricing in a Generalized Mean-Lower Partial Moment Framework: Theory and Evidence," Journal of Financial and Quantitative Analysis, 24, 285311.

Harris, L. E., 1994, "Minimum Price Variation, Discrete Bid-Ask Spreads, and Quotation Sizes," Review of Financial Studies, 7, 149-178.

Harvey, C. R., and A. Siddique, 1999, “Autoregressive Conditional Skewness,” Journal of Financial and Quantitative Analysis, 34, 465-487.

Harvey, C. R., and A. Siddique, 2000, "Conditional Skewness in Asset Pricing Tests," Journal of Finance, 55, 1263-1295.

Jahankhani, A., 1976, "E-V and E-S Capital Asset Pricing Models: Some Empirical Tests," Journal of Financial and Quantitative Analysis, 11, 513-528.

Jegadeesh, N., 1990, "Evidence of Predictable Behavior of Security Returns," Journal of Finance, 45, 881-898.

Jegadeesh, N., and S. Titman, 1993, "Returns to Buying Winners and Selling Losers: Implications for Stock Market Efficiency," Journal of Finance, 48, 65-91.

Jegadeesh, N., and S. Titman, 2001, "Profitability of Momentum Strategies: An Evaluation of Alternative Explanations," Journal of Finance, 56, 699-720.

Kahneman, D., J. L. Knetsch, and R. H. Thaler, 1990, "Experimental Tests of the Endowment Effect and the Coase Theorem," Journal of Political Economy, 99, 1325-1350.

Kelly, B., 2010, "Risk Premia and the Conditional Tails of Stock Returns,” working paper, University of Chicago.

Lehmann, B., 1990, "Fads, Martingales, and Market Efficiency," Quarterly Journal of Economics, 105, 1-28.

Markowitz, H., 1959, Portfolio Selection: Efficient Diversification of Investments. New York: Wiley. 
Newey, W. K., and K. D. West, 1987, “A Simple, Positive Semi-Definite, Heteroskedasticity and Autocorrelation Consistent Covariance Matrix," Econometrica, 55, 703-708.

Odean, T., 1999, “Do Investors Trade too Much?” American Economic Review, 89, 1279-1298.

Polkovnichenko, V., 2005, "Household Portfolio Diversification: A Case for Rank-Dependent Preferences," Review of Financial Studies, 18, 1467-1502.

Price, K., B. Price, and T. J. Nantell, 1982, "Variance and Lower Partial Moment Measures of Systematic Risk: Some Analytical and Empirical Results,” Journal of Finance, 37, 843-855.

Rietz, T. A., 1988, “The Equity Risk Premium: A Solution,” Journal of Monetary Economics, $22,117-131$.

Roche, H., S. Tompaidis, and C. Yang, 2013, "Why Does Junior Put All His Eggs in One Basket? A Potential Explanation for Holding Concentrated Portfolios," Journal of Financial Economics, 109, 775-796.

Spitzer, J., 2006, "Market Crashes, Market Booms, and the Cross-Section of Expected Returns," working paper, University of Virginia.

Subrahmanyam, A., 2010, "The Cross-Section of Expected Stock Returns: What Have We Learnt from the Past Twenty-Five Years of Research?" European Financial Management, 16, $27-42$.

Van Nieuwerburgh, S., and L. Veldkamp, 2010, "Information Acquisition and UnderDiversification," Review of Economic Studies, 77, 779-805. 


\section{Table 1. Univariate Portfolios of Stocks Sorted by Tail Risk Measures}

Decile portfolios are formed every month from July 1963 to December 2009 by sorting stocks based on three measures of tail risk over the past six months: (i) hybrid tail covariance risk (H-TCR) (equation (9)), (ii) the lower partial moment of returns $\left(\operatorname{LPM}\left(\mathrm{R}_{\mathrm{i}}\right)\right.$, equation (5)), and (iii) LPM beta with respect to the market ( $\beta_{\mathrm{LPM}}$, equation (6)). Portfolio 1 (10) is the portfolio of stocks with the lowest (highest) tail risk. We report the equal-weighted average monthly returns (in percentage terms) and the average tail risk measure for each portfolio. The last two rows present the differences in average monthly returns between portfolios 10 and 1 and the associated Newey-West (1987) adjusted t-statistics, in parentheses.

\begin{tabular}{ccccccc} 
& \multicolumn{2}{c}{ H-TCR } & \multicolumn{2}{c}{ LPM $\left(\mathrm{R}_{\mathrm{i}}\right)$} & \multicolumn{2}{c}{$\beta_{\text {LPM }}$} \\
\cline { 2 - 7 } & Return & H-TCR & Return & LPM $\left(\mathrm{R}_{\mathrm{i}}\right)$ & Return & $\beta_{\text {LPM }}$ \\
\hline Low & 0.45 & -0.266 & 1.07 & 0.070 & 0.91 & -1.428 \\
2 & 0.85 & -0.153 & 1.17 & 0.140 & 1.07 & -0.699 \\
3 & 0.95 & -0.104 & 1.19 & 0.200 & 1.10 & -0.251 \\
4 & 1.05 & -0.071 & 1.24 & 0.270 & 1.15 & 0.142 \\
5 & 1.17 & -0.044 & 1.21 & 0.350 & 1.09 & 0.527 \\
6 & 1.14 & -0.020 & 1.22 & 0.460 & 1.19 & 0.932 \\
7 & 1.15 & 0.004 & 1.13 & 0.610 & 1.15 & 1.391 \\
8 & 1.28 & 0.031 & 1.08 & 0.830 & 1.15 & 1.956 \\
9 & 1.26 & 0.064 & 0.86 & 1.230 & 0.97 & 2.746 \\
High & 1.22 & 0.124 & 0.36 & 2.530 & 0.74 & 4.225 \\
\hline Return Diff. & 0.77 & & -0.71 & & -0.17 & \\
t-stat. & $(5.29)$ & & $(-2.84)$ & & $(-0.57)$ & \\
\hline
\end{tabular}


Table 2. Descriptive Statistics for Decile Portfolios of Stocks Sorted by Tail Risk Measures

Decile portfolios are formed every month from July 1963 to December 2009 by sorting stocks based on three measures of tail risk over the past six months: (i) hybrid tail covariance risk (H-TCR) (equation (9)), (ii) the lower partial moment of returns ( $\mathrm{LPM}\left(\mathrm{R}_{\mathrm{i}}\right)$, equation (5)), and (iii) LPM beta with respect to the market $\left(\beta_{\mathrm{LPM}}\right.$, equation (6)). Portfolio $1(10)$ is the portfolio of stocks with the lowest (highest) tail risk. Panel A reports for each $\mathrm{H}$-TCR decile the average across the months in the sample of the median values within each month of various characteristics for the stocks-the three tail risk measures, the price (in dollars), the market beta, the log market capitalization, the book-to-market (BM) ratio, the cumulative return over the 6 months prior to portfolio formation (labeled MOM), the return in the portfolio formation month (labeled REV), a measure of illiquidity (scaled by $10^{5}$ ), the co-skewness (COSKEW), idiosyncratic volatility (IVOL), and the maximum daily return over the past one month (MAX). Panel B and C present the same descriptive statistics for decile portfolios of $\operatorname{LPM}\left(\mathrm{R}_{\mathrm{i}}\right)$ and $\beta_{\mathrm{LPM}}$, respectively. Panel $\mathrm{D}$ presents the time-series averages of the cross-sectional correlations of all the variables for the sample period July 1963-December 2009.

Panel A: H-TCR

\begin{tabular}{cccccccccccccc} 
& H-TCR & LPM $\left(\mathrm{R}_{\mathrm{i}}\right)$ & $\beta_{\text {LPM }}$ & Price & BETA & SIZE & BM & MOM & REV & ILLIQ & COSKEW & IVOL & MAX \\
\hline Low H-TCR & -0.252 & 1.378 & 0.405 & 17.45 & 0.77 & 4.97 & 0.60 & -0.13 & 0.14 & 0.22 & -0.05 & 2.64 & 5.79 \\
2 & -0.143 & 0.602 & 0.286 & 20.54 & 0.74 & 5.23 & 0.66 & 7.17 & 0.73 & 0.18 & -0.06 & 2.18 & 4.88 \\
3 & -0.096 & 0.413 & 0.289 & 22.55 & 0.73 & 5.43 & 0.67 & 9.28 & 0.83 & 0.14 & -0.07 & 1.97 & 4.44 \\
4 & -0.064 & 0.330 & 0.319 & 23.91 & 0.74 & 5.59 & 0.69 & 10.40 & 0.95 & 0.12 & -0.07 & 1.83 & 4.20 \\
5 & -0.038 & 0.280 & 0.400 & 25.37 & 0.76 & 5.75 & 0.70 & 11.19 & 1.06 & 0.10 & -0.08 & 1.72 & 4.00 \\
6 & -0.015 & 0.252 & 0.497 & 26.93 & 0.78 & 5.94 & 0.70 & 12.07 & 1.05 & 0.08 & -0.09 & 1.63 & 3.86 \\
7 & 0.008 & 0.250 & 0.662 & 28.29 & 0.83 & 6.11 & 0.70 & 13.08 & 1.08 & 0.07 & -0.10 & 1.57 & 3.81 \\
8 & 0.033 & 0.271 & 0.928 & 29.67 & 0.91 & 6.29 & 0.69 & 13.77 & 1.14 & 0.05 & -0.12 & 1.54 & 3.80 \\
9 & 0.066 & 0.333 & 1.388 & 30.94 & 1.03 & 6.45 & 0.67 & 15.88 & 1.16 & 0.05 & -0.13 & 1.56 & 3.95 \\
High H-TCR & 0.123 & 0.625 & 2.673 & 30.42 & 1.33 & 6.42 & 0.61 & 21.46 & 1.08 & 0.05 & -0.17 & 1.80 & 4.68 \\
\hline
\end{tabular}


Table 2 (continued)

Panel B: $\operatorname{LPM}\left(\mathbf{R}_{\mathrm{i}}\right)$

\begin{tabular}{|c|c|c|c|c|c|c|c|c|c|c|c|c|c|}
\hline & H-TCR & $\operatorname{LPM}\left(\mathrm{R}_{\mathrm{i}}\right)$ & $\beta_{\mathrm{LPM}}$ & Price & BETA & SIZE & $\mathrm{BM}$ & MOM & REV & ILLIQ & COSKEW & IVOL & MAX \\
\hline Low $\operatorname{LPM}\left(\mathrm{R}_{\mathrm{i}}\right)$ & -0.020 & 0.072 & -0.184 & 32.29 & 0.51 & 6.56 & 0.80 & 11.21 & 1.11 & 0.05 & -0.07 & 1.11 & 2.63 \\
\hline 2 & -0.022 & 0.133 & 0.174 & 30.92 & 0.65 & 6.41 & 0.74 & 11.82 & 1.14 & 0.05 & -0.08 & 1.32 & 3.16 \\
\hline 3 & -0.022 & 0.191 & 0.392 & 29.37 & 0.72 & 6.23 & 0.71 & 12.15 & 1.15 & 0.06 & -0.08 & 1.46 & 3.50 \\
\hline 4 & -0.024 & 0.256 & 0.586 & 27.96 & 0.78 & 6.04 & 0.70 & 12.40 & 1.16 & 0.07 & -0.09 & 1.60 & 3.81 \\
\hline 5 & -0.024 & 0.334 & 0.759 & 26.37 & 0.84 & 5.85 & 0.68 & 12.61 & 1.06 & 0.08 & -0.09 & 1.74 & 4.14 \\
\hline 6 & -0.026 & 0.434 & 0.955 & 24.73 & 0.90 & 5.68 & 0.66 & 13.12 & 1.15 & 0.10 & -0.10 & 1.91 & 4.51 \\
\hline 7 & -0.030 & 0.570 & 1.167 & 23.14 & 0.97 & 5.54 & 0.64 & 13.65 & 0.98 & 0.11 & -0.10 & 2.09 & 4.92 \\
\hline 8 & -0.032 & 0.776 & 1.440 & 21.70 & 1.05 & 5.39 & 0.61 & 13.55 & 0.90 & 0.12 & -0.11 & 2.30 & 5.40 \\
\hline 9 & -0.045 & 1.153 & 1.710 & 20.15 & 1.14 & 5.24 & 0.58 & 12.37 & 0.63 & 0.14 & -0.11 & 2.55 & 5.94 \\
\hline $\operatorname{High} \operatorname{LPM}\left(\mathrm{R}_{\mathrm{i}}\right)$ & -0.103 & 2.374 & 2.119 & 17.28 & 1.27 & 5.05 & 0.54 & 3.92 & -0.48 & 0.16 & -0.10 & 2.96 & 6.70 \\
\hline
\end{tabular}

Panel C: $\boldsymbol{\beta}_{\mathrm{LPM}}$

\begin{tabular}{|c|c|c|c|c|c|c|c|c|c|c|c|c|c|}
\hline & H-TCR & $\operatorname{LPM}\left(\mathrm{R}_{\mathrm{i}}\right)$ & $\beta_{\text {LPM }}$ & Price & BETA & SIZE & $\mathrm{BM}$ & MOM & REV & ILLIQ & COSKEW & IVOL & MAX \\
\hline Low $\beta_{\text {LPM }}$ & -0.098 & 0.258 & -1.349 & 24.43 & 0.38 & 5.37 & 0.77 & 13.03 & 1.76 & 0.19 & -0.01 & 1.64 & 3.65 \\
\hline 2 & -0.067 & 0.214 & -0.626 & 26.51 & 0.48 & 5.71 & 0.76 & 11.19 & 1.25 & 0.13 & -0.05 & 1.44 & 3.27 \\
\hline 3 & -0.052 & 0.233 & -0.188 & 27.05 & 0.59 & 5.87 & 0.74 & 10.71 & 1.14 & 0.10 & -0.07 & 1.48 & 3.41 \\
\hline 4 & -0.040 & 0.259 & 0.187 & 27.08 & 0.68 & 5.94 & 0.71 & 10.36 & 1.01 & 0.08 & -0.08 & 1.56 & 3.63 \\
\hline 5 & -0.028 & 0.294 & 0.556 & 27.06 & 0.79 & 6.00 & 0.68 & 10.69 & 0.97 & 0.07 & -0.09 & 1.63 & 3.84 \\
\hline 6 & -0.015 & 0.337 & 0.941 & 26.56 & 0.89 & 6.00 & 0.66 & 10.60 & 0.89 & 0.07 & -0.10 & 1.72 & 4.10 \\
\hline 7 & -0.002 & 0.400 & 1.375 & 26.06 & 1.00 & 5.96 & 0.64 & 11.17 & 0.79 & 0.07 & -0.11 & 1.84 & 4.42 \\
\hline 8 & 0.014 & 0.497 & 1.913 & 24.83 & 1.15 & 5.87 & 0.61 & 12.60 & 0.67 & 0.08 & -0.13 & 2.00 & 4.86 \\
\hline 9 & 0.035 & 0.660 & 2.666 & 23.43 & 1.35 & 5.73 & 0.58 & 14.63 & 0.52 & 0.08 & -0.13 & 2.26 & 5.56 \\
\hline High $\beta_{\text {LPM }}$ & 0.082 & 1.101 & 4.105 & 20.32 & 1.71 & 5.44 & 0.53 & 20.44 & 0.12 & 0.10 & -0.15 & 2.72 & 6.82 \\
\hline
\end{tabular}


Table 2 (continued)

Panel D: Average Firm-Level Correlations

\begin{tabular}{|c|c|c|c|c|c|c|c|c|c|c|c|c|}
\hline & H-TCR & $\operatorname{LPM}\left(\mathrm{R}_{\mathrm{i}}\right)$ & $\beta_{\text {LPM }}$ & BETA & SIZE & $\mathrm{BM}$ & MOM & REV & ILLIQ & COSKEW & IVOL & MAX \\
\hline H-TCR & 1 & -0.390 & 0.342 & 0.230 & 0.278 & 0.002 & 0.115 & 0.022 & -0.112 & -0.130 & -0.277 & -0.152 \\
\hline $\operatorname{LPM}\left(\mathrm{R}_{\mathrm{i}}\right)$ & & 1 & 0.292 & 0.259 & -0.195 & -0.058 & -0.075 & -0.045 & 0.029 & -0.038 & 0.421 & 0.286 \\
\hline$\beta_{\mathrm{LPM}}$ & & & 1 & 0.719 & -0.001 & -0.102 & -0.021 & -0.056 & -0.083 & -0.250 & 0.307 & 0.267 \\
\hline BETA & & & & 1 & 0.076 & -0.141 & 0.017 & -0.007 & -0.127 & 0.015 & 0.347 & 0.325 \\
\hline SIZE & & & & & 1 & -0.142 & -0.012 & -0.009 & -0.265 & 0.052 & -0.355 & -0.255 \\
\hline $\mathrm{BM}$ & & & & & & 1 & 0.053 & 0.028 & 0.121 & -0.002 & -0.045 & -0.028 \\
\hline MOM & & & & & & & 1 & 0.007 & -0.023 & -0.063 & 0.033 & 0.016 \\
\hline REV & & & & & & & & 1 & 0.029 & -0.003 & 0.177 & 0.398 \\
\hline ILLIQ & & & & & & & & & 1 & -0.009 & 0.082 & 0.058 \\
\hline COSKEW & & & & & & & & & & 1 & -0.019 & 0.001 \\
\hline IVOL & & & & & & & & & & & 1 & 0.851 \\
\hline MAX & & & & & & & & & & & & 1 \\
\hline
\end{tabular}




\section{Table 3. Firm-Level Cross-Sectional Return Regressions}

Each month from July 1963 to December 2009 we run a firm-level cross-sectional regression of the one-month ahead return on lagged predictor variables including our tail risk measures - H-TCR, LPM $\left(R_{i}\right)$, and $\beta_{L P M},-$ the Fama-French-Carhart factors (in Panel A), and five other control variables (in Panel B). The variables are defined in the Appendix. Two alternative definitions of momentum are used; MOM is the 6-month cumulative return from month $t-7$ to month $t-2$, and MOM12 is the 11-month cumulative return from month $t-12$ to month $t-2$. In each row, Panels A and B report the time series averages of the cross-sectional regression slope coefficients and their associated Newey-West (1987) adjusted t-statistics (in parentheses).

Panel A. Standard Specifications

\begin{tabular}{cccccccc}
\hline \multicolumn{2}{c}{ Tail Risk Measure } & \multicolumn{5}{c}{ Fama-French-Carhart Factors } \\
\hline H-TCR & LPM $\left(\mathrm{R}_{\mathrm{i}}\right)$ & $\beta_{\text {LPM }}$ & BETA & SIZE & BM & MOM & MOM12 \\
\hline 2.8797 & & & & & & & \\
$(4.77)$ & & & & & & & \\
& -0.0775 & & & & & & \\
& $(-0.76)$ & & & & & & \\
& & 0.0009 & & & & & \\
2.2870 & & $(0.02)$ & & & & & \\
$(5.63)$ & & & -0.1557 & -0.0905 & 0.1480 & 0.8489 & \\
& -0.1999 & & $-0.90)$ & $(-2.12)$ & $(2.22)$ & $(4.12)$ & \\
& $(-4.43)$ & & -0.0346 & -0.0810 & 0.1541 & 0.8899 & \\
& & -0.0112 & -0.0999 & -0.0549 & 0.1700 & 0.9019 & \\
& & $(-0.32)$ & $(-0.65)$ & $(-1.23)$ & $(2.53)$ & $(4.29)$ & \\
2.1844 & & & -0.1842 & -0.0882 & 0.1711 & & 0.7615 \\
$(5.53)$ & & & $(-1.09)$ & $(-2.04)$ & $(2.66)$ & & $(4.94)$ \\
& & & & & & & \\
& -0.2104 & & -0.0635 & -0.0815 & 0.1757 & & 0.7924 \\
& $(-4.63)$ & & $(-0.39)$ & $(-1.81)$ & $(2.70)$ & & $(5.03)$ \\
& & -0.0163 & -0.1211 & -0.0548 & 0.1929 & & 0.7902 \\
& & $(-0.46)$ & $(-0.80)$ & $(-1.21)$ & $(2.96)$ & & $(5.05)$ \\
\hline
\end{tabular}


Table 3 (continued)

Panel B: Specifications with Additional Control Variables

\begin{tabular}{|c|c|c|c|c|c|c|c|c|c|}
\hline \multicolumn{10}{|l|}{ Tail Risk } \\
\hline \multirow{2}{*}{$\begin{array}{c}\text { Measure } \\
\text { H-TCR } \\
\end{array}$} & \multicolumn{4}{|c|}{ Fama-French-Carhart Factors } & \multicolumn{5}{|c|}{ Additional Control Variables } \\
\hline & BETA & SIZE & $\mathrm{BM}$ & MOM & REV & ILLIQ & COSKEW & IVOL & MAX \\
\hline 2.4575 & -0.1509 & -0.0906 & 0.1680 & 0.7730 & -3.8010 & & & & \\
\hline$(5.91)$ & $(-0.85)$ & $(-2.09)$ & $(2.44)$ & $(3.57)$ & $(-8.44)$ & & & & \\
\hline 2.2233 & -0.1699 & -0.1057 & 0.1487 & 0.8375 & & -0.1768 & & & \\
\hline$(5.47)$ & $(-0.98)$ & $(-2.42)$ & $(2.23)$ & $(4.05)$ & & $(-2.09)$ & & & \\
\hline 2.2436 & -0.1643 & -0.0933 & 0.1420 & 0.8566 & & & -0.0725 & & \\
\hline$(5.43)$ & $(-0.92)$ & $(-2.24)$ & $(2.16)$ & $(4.21)$ & & & $(-0.30)$ & & \\
\hline 1.2336 & 0.0785 & -0.1559 & 0.1219 & 0.8786 & & & & -0.2820 & \\
\hline$(3.48)$ & $(0.48)$ & $(-3.81)$ & $(1.86)$ & $(4.29)$ & & & & $(-9.09)$ & \\
\hline 1.6471 & 0.0612 & -0.1394 & 0.1332 & 0.8362 & & & & & -8.7523 \\
\hline$(4.42)$ & $(0.37)$ & $(-3.32)$ & $(2.02)$ & $(4.03)$ & & & & & $(-9.92)$ \\
\hline $\operatorname{LPM}\left(\mathrm{R}_{\mathrm{i}}\right)$ & BETA & SIZE & $\mathrm{BM}$ & MOM & REV & ILLIQ & COSKEW & IVOL & MAX \\
\hline-0.2233 & -0.0154 & -0.0813 & 0.1733 & 0.8193 & -3.8643 & & & & \\
\hline$(-4.72)$ & $(-0.09)$ & $(-1.80)$ & $(2.49)$ & $(3.72)$ & $(-8.63)$ & & & & \\
\hline-0.1930 & -0.0520 & -0.0970 & 0.1548 & 0.8766 & & -0.1851 & & & \\
\hline$(-4.25)$ & $(-0.31)$ & $(-2.13)$ & $(2.30)$ & $(4.16)$ & & $(-2.15)$ & & & \\
\hline-0.2004 & -0.0649 & -0.0834 & 0.1463 & 0.8883 & & & -0.3020 & & \\
\hline$(-4.49)$ & $(-0.38)$ & $(-1.93)$ & $(2.20)$ & $(4.28)$ & & & $(-1.26)$ & & \\
\hline-0.0987 & 0.1285 & -0.1522 & 0.1239 & 0.9092 & & & & -0.2890 & \\
\hline$(-2.26)$ & $(0.81)$ & $(-3.66)$ & $(1.89)$ & $(4.37)$ & & & & $(-8.95)$ & \\
\hline-0.1347 & 0.1433 & -0.1338 & 0.1372 & 0.8652 & & & & & -9.0479 \\
\hline$(-2.94)$ & $(0.88)$ & $(-3.10)$ & $(2.07)$ & $(4.10)$ & & & & & $(-10.05)$ \\
\hline$\beta_{\mathrm{LPM}}$ & BETA & SIZE & $\mathrm{BM}$ & MOM & REV & ILLIQ & COSKEW & IVOL & MAX \\
\hline-0.0251 & -0.0402 & -0.0546 & 0.1909 & 0.8402 & -3.7748 & & & & \\
\hline$(-0.80)$ & $(-0.26)$ & $(-1.21)$ & $(2.75)$ & $(3.83)$ & $(-8.59)$ & & & & \\
\hline-0.0132 & -0.1118 & -0.0712 & 0.1706 & 0.8887 & & -0.1708 & & & \\
\hline$(-0.38)$ & $(-0.73)$ & $(-1.56)$ & $(2.53)$ & $(4.21)$ & & $(-2.11)$ & & & \\
\hline-0.0670 & -0.0433 & -0.0701 & 0.1594 & 0.9102 & & & -0.3702 & & \\
\hline$(-1.73)$ & $(-0.25)$ & $(-1.62)$ & $(2.39)$ & $(4.40)$ & & & $(-1.48)$ & & \\
\hline 0.0080 & 0.0667 & -0.1426 & 0.1278 & 0.9032 & & & & -0.3108 & \\
\hline$(0.23)$ & $(0.46)$ & $(-3.46)$ & $(1.96)$ & $(4.35)$ & & & & $(-9.64)$ & \\
\hline-0.0024 & 0.0835 & -0.1162 & 0.1468 & 0.8665 & & & & & -9.4371 \\
\hline$(-0.07)$ & $(0.57)$ & $(-2.69)$ & $(2.22)$ & $(4.11)$ & & & & & $(-10.32)$ \\
\hline
\end{tabular}




\section{Table 4. Tail Risk Measures for Differing Tail Sizes}

We report the average slope coefficients, over the sample period July 1963 to December 2009, and associated Newey-West t-statistics (in parentheses) on our three tail risk measures- H-TCR, $\operatorname{LPM}\left(\mathrm{R}_{\mathrm{i}}\right)$, and $\beta_{\mathrm{LPM}}$ - from Fama-MacBeth regressions of one-month ahead returns on tail risk after controlling for market beta, size, book-to-market, and momentum, i.e., the four Fama-French-Carhart factors. For the sake of brevity, results for the factors are not reported. Tail risk measures for the 5\%,10\%, 20\%, 30\%, 40\%, and 50\% tails are calculated using daily returns over the past one year.

\begin{tabular}{ccccccc} 
& $5 \%$ & $10 \%$ & $20 \%$ & $30 \%$ & $40 \%$ & $50 \%$ \\
\hline \multirow{2}{*}{ H-TCR } & 1.2221 & 1.1493 & 0.9400 & 0.7474 & 0.5526 & -0.1519 \\
& $(3.73)$ & $(4.09)$ & $(3.61)$ & $(3.18)$ & $(2.90)$ & $(-0.88)$ \\
\multirow{2}{*}{$\mathrm{LPM}\left(\mathrm{R}_{\mathrm{i}}\right)$} & -0.1125 & -0.1216 & -0.1031 & -0.0872 & -0.0592 & -0.0624 \\
& $(-3.72)$ & $(-4.66)$ & $(-5.13)$ & $(-5.50)$ & $(-5.07)$ & $(-5.45)$ \\
\multirow{3}{*}{$\beta_{\text {LPM }}$} & -0.0303 & -0.0424 & -0.0686 & -0.0800 & -0.0514 & -0.0506 \\
& $(-1.08)$ & $(-0.89)$ & $(-0.72)$ & $(-0.53)$ & $(-0.23)$ & $(-0.17)$ \\
\hline
\end{tabular}




\section{Table 5. Time-Series Average of the H-TCR Transition Matrix}

Decile portfolios are formed every month from July 1963 to December 2009 by sorting stocks based on the hybrid tail covariance risk (H-TCR) over the past six months. Panel A reports the average of the month-to-month transition matrices for the stocks in these portfolios, i.e., the average probability (in percent) that a stock in decile $i$ (as given by the rows of the matrix) in one month will be in decile $j$ (as given by the columns of the matrix) in the subsequent month. We roll the sample month by month (hence there is an overlap in the calculation of H-TCR) and the transition matrices are computed for each month in our sample, generating a total of 558 matrices. Panel B reports the average of the 6-month lag transition matrices for the stocks in these portfolios, i.e., the average probability (in percent) that a stock in decile $i$ (as given by the rows of the matrix) in one month will be in decile $j$ (as given by the columns of the matrix) 6 months later.

Panel A. One Month Lag

\begin{tabular}{ccccccccccc} 
& \multicolumn{1}{c}{ Low H-TCR } & 2 & 3 & 4 & 5 & 6 & 7 & 8 & 9 & High H-TCR \\
\cline { 2 - 10 } Low H-TCR & $71.94 \%$ & $16.44 \%$ & $4.45 \%$ & $2.18 \%$ & $1.35 \%$ & $0.97 \%$ & $0.66 \%$ & $0.52 \%$ & $0.40 \%$ & $0.36 \%$ \\
2 & $16.29 \%$ & $47.34 \%$ & $19.56 \%$ & $7.42 \%$ & $3.64 \%$ & $2.14 \%$ & $1.41 \%$ & $0.96 \%$ & $0.71 \%$ & $0.51 \%$ \\
3 & $4.68 \%$ & $19.19 \%$ & $37.33 \%$ & $19.90 \%$ & $8.43 \%$ & $4.46 \%$ & $2.54 \%$ & $1.61 \%$ & $1.10 \%$ & $0.76 \%$ \\
4 & $2.33 \%$ & $7.36 \%$ & $19.58 \%$ & $32.64 \%$ & $19.32 \%$ & $8.92 \%$ & $4.73 \%$ & $2.65 \%$ & $1.54 \%$ & $1.01 \%$ \\
5 & $1.44 \%$ & $3.70 \%$ & $8.50 \%$ & $18.87 \%$ & $31.01 \%$ & $18.98 \%$ & $9.11 \%$ & $4.64 \%$ & $2.55 \%$ & $1.32 \%$ \\
6 & $1.06 \%$ & $2.25 \%$ & $4.43 \%$ & $8.89 \%$ & $18.59 \%$ & $31.09 \%$ & $18.79 \%$ & $8.67 \%$ & $4.33 \%$ & $2.07 \%$ \\
7 & $0.78 \%$ & $1.42 \%$ & $2.65 \%$ & $4.71 \%$ & $9.01 \%$ & $18.44 \%$ & $32.80 \%$ & $19.15 \%$ & $7.99 \%$ & $3.20 \%$ \\
8 & $0.57 \%$ & $0.99 \%$ & $1.66 \%$ & $2.72 \%$ & $4.72 \%$ & $8.67 \%$ & $18.72 \%$ & $36.70 \%$ & $19.41 \%$ & $5.99 \%$ \\
9 & $0.50 \%$ & $0.75 \%$ & $1.07 \%$ & $1.68 \%$ & $2.60 \%$ & $4.29 \%$ & $8.04 \%$ & $18.87 \%$ & $44.45 \%$ & $17.89 \%$ \\
High H-TCR & $0.41 \%$ & $0.56 \%$ & $0.77 \%$ & $0.99 \%$ & $1.32 \%$ & $2.05 \%$ & $3.21 \%$ & $6.23 \%$ & $17.52 \%$ & $66.88 \%$ \\
\hline
\end{tabular}


Table 5 (continued)

Panel B. Six Month Lag

\begin{tabular}{|c|c|c|c|c|c|c|c|c|c|c|}
\hline & Low H-TCR & 2 & 3 & 4 & 5 & 6 & 7 & 8 & 9 & High H-TCR \\
\hline Low H-TCR & $23.04 \%$ & $15.81 \%$ & $12.33 \%$ & $10.07 \%$ & $8.47 \%$ & $7.33 \%$ & $6.24 \%$ & $5.50 \%$ & $5.30 \%$ & $5.91 \%$ \\
\hline 2 & $15.31 \%$ & $14.10 \%$ & $12.82 \%$ & $11.39 \%$ & $10.07 \%$ & $8.91 \%$ & $7.72 \%$ & $6.97 \%$ & $6.36 \%$ & $6.34 \%$ \\
\hline 3 & $12.11 \%$ & $12.38 \%$ & $12.05 \%$ & $11.57 \%$ & $10.90 \%$ & $9.95 \%$ & $9.07 \%$ & $8.23 \%$ & $7.11 \%$ & $6.63 \%$ \\
\hline 4 & $10.02 \%$ & $11.18 \%$ & $11.54 \%$ & $11.49 \%$ & $11.10 \%$ & $10.65 \%$ & $9.93 \%$ & $9.02 \%$ & $7.94 \%$ & $7.12 \%$ \\
\hline 5 & $8.19 \%$ & $9.95 \%$ & $10.71 \%$ & $10.92 \%$ & $11.22 \%$ & $11.14 \%$ & $10.77 \%$ & $9.97 \%$ & $9.07 \%$ & $8.06 \%$ \\
\hline 6 & $7.28 \%$ & $8.99 \%$ & $9.74 \%$ & $10.61 \%$ & $10.95 \%$ & $11.15 \%$ & $11.17 \%$ & $10.95 \%$ & $10.24 \%$ & $8.92 \%$ \\
\hline 7 & $6.45 \%$ & $7.85 \%$ & $8.96 \%$ & $9.92 \%$ & $10.57 \%$ & $11.37 \%$ & $11.41 \%$ & $11.71 \%$ & $11.54 \%$ & $10.21 \%$ \\
\hline 8 & $5.78 \%$ & $6.96 \%$ & $8.01 \%$ & $8.86 \%$ & $9.94 \%$ & $10.80 \%$ & $11.87 \%$ & $12.43 \%$ & $12.98 \%$ & $12.35 \%$ \\
\hline 9 & $5.50 \%$ & $6.41 \%$ & $7.18 \%$ & $8.02 \%$ & $8.88 \%$ & $9.86 \%$ & $11.51 \%$ & $12.92 \%$ & $14.57 \%$ & $15.16 \%$ \\
\hline High H-TCR & $6.31 \%$ & $6.36 \%$ & $6.67 \%$ & $7.15 \%$ & $7.89 \%$ & $8.84 \%$ & $10.30 \%$ & $12.31 \%$ & $14.88 \%$ & $19.28 \%$ \\
\hline
\end{tabular}




\section{Table 6. Alternative Measures of Hybrid Tail Covariance Risk}

In Panel A, decile portfolios are formed every month from July 1963 to December 2009 by sorting stocks based on alternative measures of hybrid tail covariance risk (H-TCR). H-TCR is computed based on returns from the (i) 5\% lower tail of the daily return distribution over the past 12 months; (ii) $10 \%$ lower tail of the daily return distribution over the past 12 months; (iii) 10\% lower tail of the daily return distribution over the past 6 months; (iv) $20 \%$ lower tail of the daily return distribution over the past 6 months; and (v) 20\% lower tail of the daily return distribution over the past 3 months. Portfolio 1 (10) is the portfolio of stocks with the lowest (highest) H-TCR. The table reports the average monthly returns (in percentage terms) and average H-TCR values in each decile. The last four rows present the differences in monthly returns and the differences in alphas with respect to the 4factor Fama-French-Carhart model (FFC4 Alpha) between portfolios 10 and 1, with associated Newey-West (1987) adjusted t-statistics in parentheses. In Panel B, we repeat the same exercise except that stocks are sorted on the basis of hybrid tail beta, as given in equation (13), rather than TCR.

Panel A: Alternative Measures of Tail Covariance Risk

\begin{tabular}{|c|c|c|c|c|c|c|c|c|c|c|}
\hline & \multicolumn{2}{|c|}{$5 \%$ H-TCR in 12 months } & \multicolumn{2}{|c|}{$10 \% \mathrm{H}-\mathrm{TCR}$ in 12 months } & \multicolumn{2}{|c|}{$10 \% \mathrm{H}-\mathrm{TCR}$ in 6 months } & \multicolumn{2}{|c|}{$20 \%$ H-TCR in 6 months } & \multicolumn{2}{|c|}{$20 \% \mathrm{H}-\mathrm{TCR}$ in 3 months } \\
\hline & Return & H-TCR & Return & H-TCR & Return & H-TCR & Return & H-TCR & Return & H-TCR \\
\hline Low H-TCR & 0.64 & -0.408 & 0.65 & -0.456 & 0.45 & -0.266 & 0.54 & -0.251 & 0.49 & -0.155 \\
\hline 2 & 0.91 & -0.241 & 0.95 & -0.273 & 0.85 & -0.153 & 0.91 & -0.131 & 0.84 & -0.081 \\
\hline 3 & 1.03 & -0.167 & 1.03 & -0.188 & 0.95 & -0.104 & 0.99 & -0.074 & 0.99 & -0.048 \\
\hline 4 & 1.10 & -0.118 & 1.01 & -0.127 & 1.05 & -0.071 & 1.07 & -0.032 & 1.04 & -0.025 \\
\hline 5 & 1.13 & -0.079 & 1.13 & -0.077 & 1.17 & -0.044 & 1.13 & 0.003 & 1.10 & -0.006 \\
\hline 6 & 1.17 & -0.044 & 1.21 & -0.032 & 1.14 & -0.020 & 1.15 & 0.037 & 1.12 & 0.012 \\
\hline 7 & 1.21 & -0.011 & 1.20 & 0.013 & 1.15 & 0.004 & 1.18 & 0.072 & 1.19 & 0.031 \\
\hline 8 & 1.18 & 0.025 & 1.22 & 0.064 & 1.28 & 0.031 & 1.21 & 0.113 & 1.26 & 0.052 \\
\hline 9 & 1.21 & 0.071 & 1.17 & 0.128 & 1.26 & 0.064 & 1.20 & 0.167 & 1.27 & 0.081 \\
\hline High H-TCR & 1.14 & 0.148 & 1.14 & 0.238 & 1.22 & 0.124 & 1.12 & 0.265 & 1.23 & 0.134 \\
\hline Return Diff. & 0.51 & & 0.48 & & 0.77 & & 0.59 & & 0.74 & \\
\hline t-stat. & $(3.19)$ & & $(2.76)$ & & $(5.29)$ & & $(3.37)$ & & $(5.20)$ & \\
\hline FFC4 Alpha Diff. & 0.51 & & 0.54 & & 0.69 & & 0.51 & & 0.63 & \\
\hline t-stat. & $(3.83)$ & & $(3.66)$ & & $(5.24)$ & & $(3.29)$ & & $(4.42)$ & \\
\hline
\end{tabular}




\section{Table 6 (continued)}

Panel B: Hybrid Tail Beta

\begin{tabular}{|c|c|c|c|c|c|c|c|c|c|c|}
\hline & \multicolumn{2}{|c|}{$\begin{array}{l}5 \% \text { Tail Beta } \\
\text { in } 12 \text { months }\end{array}$} & \multicolumn{2}{|c|}{$\begin{array}{l}10 \% \text { Tail Beta } \\
\text { in } 12 \text { months }\end{array}$} & \multicolumn{2}{|c|}{$\begin{array}{c}10 \% \text { Tail Beta } \\
\text { in } 6 \text { months }\end{array}$} & \multicolumn{2}{|c|}{$\begin{array}{c}20 \% \text { Tail Beta } \\
\text { In } 6 \text { months }\end{array}$} & \multicolumn{2}{|c|}{$\begin{array}{c}20 \% \text { Tail Beta } \\
\text { in } 3 \text { months }\end{array}$} \\
\hline & Return & Tail Beta & Return & Tail Beta & Return & Tail Beta & Return & Tail Beta & Return & Tail Beta \\
\hline Low Tail Beta & 0.67 & -1.82 & 0.57 & -1.46 & 0.48 & -1.77 & 0.55 & -1.21 & 0.45 & -1.57 \\
\hline 2 & 0.85 & -1.16 & 0.96 & -0.97 & 0.82 & -1.10 & 0.88 & -0.72 & 0.87 & -0.91 \\
\hline 3 & 1.08 & -0.88 & 1.05 & -0.74 & 0.97 & -0.82 & 1.00 & -0.50 & 0.98 & -0.62 \\
\hline 4 & 1.10 & -0.69 & 1.04 & -0.58 & 1.08 & -0.63 & 1.10 & -0.34 & 0.98 & -0.43 \\
\hline 5 & 1.07 & -0.55 & 1.12 & -0.45 & 1.12 & -0.48 & 1.12 & -0.21 & 1.13 & -0.27 \\
\hline 6 & 1.13 & -0.44 & 1.18 & -0.34 & 1.11 & -0.36 & 1.16 & -0.09 & 1.14 & -0.13 \\
\hline 7 & 1.18 & -0.32 & 1.21 & -0.23 & 1.15 & -0.23 & 1.16 & 0.05 & 1.19 & 0.02 \\
\hline 8 & 1.19 & -0.20 & 1.21 & -0.10 & 1.25 & -0.09 & 1.25 & 0.20 & 1.28 & 0.21 \\
\hline 9 & 1.24 & -0.05 & 1.21 & 0.07 & 1.30 & 0.10 & 1.18 & 0.42 & 1.28 & 0.47 \\
\hline High Tail Beta & 1.19 & 0.27 & 1.16 & 0.41 & 1.24 & 0.51 & 1.11 & 0.87 & 1.23 & 1.03 \\
\hline Return Diff. & 0.52 & & 0.59 & & 0.77 & & 0.56 & & 0.78 & \\
\hline t-stat. & $(3.20)$ & & $(3.46)$ & & $(5.06)$ & & $(3.27)$ & & $(5.67)$ & \\
\hline FFC4 Alpha Diff. & 0.50 & & 0.59 & & 0.64 & & 0.44 & & 0.62 & \\
\hline t-stat. & $(3.56)$ & & $(3.80)$ & & $(4.43)$ & & $(2.70)$ & & $(4.44)$ & \\
\hline
\end{tabular}




\section{Table 7. Returns on Portfolios of Stocks Sorted by H-TCR after Controlling for SIZE, BM, MOM, REV, ILLIQ, COSKEW, IVOL, and MAX}

Double-sorted, equal-weighted decile portfolios are formed every month from July 1963 to December 2009 by sorting stocks based on the hybrid tail covariance risk after controlling for size, book-to-market, intermediate-term momentum, short-term reversal, illiquidity, co-skewness, idiosyncratic volatility, and MAX. In each case, we first sort the stocks into deciles using the control variable, then within, each decile, we sort stocks into decile portfolios based on the hybrid tail covariance risk over the previous year so that decile 1 (10) contains stocks with the lowest (highest) H-TCR. The table presents average returns (in percentage terms) across the 10 control deciles to produce decile portfolios with dispersion in H-TCR but with similar levels of the control variable. The last four rows present the differences in monthly returns and the differences in alphas with respect to the 4-factor Fama-French-Carhart model (FFC4 Alpha) between portfolios 10 and 1, with associated Newey-West t-statistics in parentheses.

\begin{tabular}{|c|c|c|c|c|c|c|c|c|}
\hline & SIZE & $\mathrm{BM}$ & MOM & REV & ILLIQ & COSKEW & IVOL & MAX \\
\hline \multirow[t]{2}{*}{ Low H-TCR } & 0.55 & 0.69 & 0.77 & 0.62 & 0.58 & 0.64 & 0.77 & 0.82 \\
\hline & $(2.11)$ & $(2.49)$ & $(2.93)$ & $(2.25)$ & (2.09) & $(2.30)$ & (3.11) & (3.16) \\
\hline \multirow[t]{2}{*}{2} & 0.86 & 0.88 & 0.93 & 0.86 & 0.91 & 0.93 & 0.96 & 0.90 \\
\hline & $(3.42)$ & $(3.41)$ & $(3.61)$ & $(3.34)$ & $(3.55)$ & (3.59) & $(4.08)$ & (3.57) \\
\hline \multirow[t]{2}{*}{3} & 0.94 & 1.00 & 1.03 & 1.01 & 0.99 & 1.06 & 1.04 & 0.95 \\
\hline & $(3.95)$ & $(4.00)$ & $(4.28)$ & $(4.08)$ & $(4.00)$ & $(4.27)$ & $(4.38)$ & (3.90) \\
\hline \multirow[t]{2}{*}{4} & 1.04 & 1.05 & 1.05 & 1.04 & 1.03 & 1.07 & 1.03 & 1.06 \\
\hline & $(4.42)$ & $(4.34)$ & $(4.37)$ & $(4.42)$ & $(4.26)$ & $(4.37)$ & $(4.42)$ & (4.47) \\
\hline \multirow[t]{2}{*}{5} & 1.13 & 1.09 & 1.07 & 1.12 & 1.14 & 1.06 & 1.04 & 1.06 \\
\hline & $(4.82)$ & $(4.64)$ & $(4.59)$ & $(4.70)$ & $(4.85)$ & $(4.51)$ & $(4.42)$ & (4.45) \\
\hline \multirow[t]{2}{*}{6} & 1.08 & 1.11 & 1.11 & 1.17 & 1.14 & 1.10 & 1.10 & 1.06 \\
\hline & $(4.61)$ & $(4.72)$ & $(4.66)$ & $(5.10)$ & $(5.00)$ & $(4.71)$ & $(4.55)$ & (4.44) \\
\hline \multirow[t]{2}{*}{7} & 1.20 & 1.17 & 1.15 & 1.12 & 1.17 & 1.16 & 1.17 & 1.17 \\
\hline & $(5.10)$ & $(5.13)$ & $(4.95)$ & $(4.88)$ & $(5.05)$ & $(5.08)$ & $(4.82)$ & (4.94) \\
\hline \multirow[t]{2}{*}{8} & 1.30 & 1.21 & 1.22 & 1.29 & 1.23 & 1.21 & 1.18 & 1.22 \\
\hline & $(5.43)$ & $(5.10)$ & $(5.08)$ & $(5.37)$ & $(5.27)$ & (5.20) & $(4.67)$ & (4.99) \\
\hline \multirow[t]{2}{*}{9} & 1.27 & 1.22 & 1.21 & 1.18 & 1.24 & 1.22 & 1.17 & 1.19 \\
\hline & $(5.11)$ & $(5.12)$ & $(4.92)$ & $(4.91)$ & $(5.07)$ & $(5.19)$ & $(4.55)$ & (4.83) \\
\hline \multirow[t]{2}{*}{ High H-TCR } & 1.28 & 1.25 & 1.11 & 1.24 & 1.23 & 1.19 & 1.19 & 1.22 \\
\hline & (4.39) & $(4.58)$ & (3.98) & $(4.44)$ & $(4.36)$ & $(4.36)$ & $(4.27)$ & $(4.52)$ \\
\hline Return Diff. & 0.73 & 0.56 & 0.35 & 0.63 & 0.65 & 0.55 & 0.42 & 0.40 \\
\hline t-stat. & $(5.62)$ & $(4.08)$ & $(2.55)$ & $(4.50)$ & $(4.73)$ & $(4.05)$ & $(3.27)$ & $(3.22)$ \\
\hline FFC4 Alpha Diff. & 0.53 & 0.49 & 0.40 & 0.56 & 0.50 & 0.51 & 0.34 & 0.35 \\
\hline $\mathrm{t}$-stat. & $(4.18)$ & $(3.81)$ & $(3.18)$ & $(4.40)$ & $(3.74)$ & $(4.32)$ & $(2.96)$ & (3.14) \\
\hline
\end{tabular}


Table 8. Characteristic Matched Portfolios of Stocks Sorted by H-TCR: Additional Controls for SIZE/BM and MOM, REV, ILLIQ, COSKEW, IVOL, and MAX

In the column labeled "Size/BM adjusted," we report the average returns of H-TCR portfolios in excess of the size and book-to-market matched benchmark portfolios similar to Daniel and Titman (1997) for the sample period July 1963 to December 2009. In the next six columns, we include additional controls for momentum, short-term reversal, illiquidity, co-skewness, idiosyncratic volatility, and MAX. For each additional control, we first perform a decile sort based on the characteristic and then on hybrid tail covariance risk (H-TCR). Then, we average the H-TCR deciles across the characteristic deciles and report size and book-to-market matched returns within each H-TCR decile. Portfolio 1 (10) is the portfolio of stocks with the lowest (highest) tail covariance risk. We report the average returns in monthly percentage terms. The last two rows report the difference in returns between portfolios 10 and 1 with associated Newey-West $t$-statistics in parentheses.

\begin{tabular}{|c|c|c|c|c|c|c|c|}
\hline & \multirow[b]{2}{*}{ SIZE/BM Adjusted } & \multicolumn{6}{|c|}{ Additional Controls } \\
\hline & & MOM & REV & ILLIQ & COSKEW & IVOL & MAX \\
\hline Low H-TCR & -0.41 & -0.24 & -0.40 & -0.39 & -0.37 & -0.29 & -0.22 \\
\hline 2 & -0.17 & -0.13 & -0.21 & -0.14 & -0.15 & -0.09 & -0.17 \\
\hline 3 & -0.08 & -0.03 & -0.06 & -0.05 & -0.01 & -0.05 & -0.10 \\
\hline 4 & 0.00 & -0.02 & 0.00 & -0.02 & 0.02 & -0.02 & 0.00 \\
\hline 5 & 0.08 & -0.01 & 0.04 & 0.06 & 0.01 & -0.04 & -0.02 \\
\hline 6 & 0.02 & 0.03 & 0.07 & 0.06 & 0.01 & 0.02 & 0.00 \\
\hline 7 & 0.06 & 0.06 & 0.05 & 0.08 & 0.07 & 0.09 & 0.07 \\
\hline 8 & 0.16 & 0.14 & 0.17 & 0.12 & 0.13 & 0.11 & 0.13 \\
\hline 9 & 0.15 & 0.11 & 0.16 & 0.12 & 0.13 & 0.10 & 0.12 \\
\hline High H-TCR & 0.18 & 0.11 & 0.19 & 0.16 & 0.17 & 0.18 & 0.19 \\
\hline Return Diff. & 0.59 & 0.35 & 0.60 & 0.55 & 0.54 & 0.46 & 0.42 \\
\hline t-stat. & $(5.35)$ & $(3.53)$ & $(5.83)$ & $(5.33)$ & $(5.70)$ & $(4.44)$ & (4.37) \\
\hline
\end{tabular}




\section{Table 9. Portfolios of Stocks Sorted by Hybrid Tail Covariance Risk after Screening for}

Liquidity, Idiosyncratic Volatility, Winners, Losers, Momentum, and Reversal

We form equal-weighted decile portfolios every month from July 1963 to December 2009 by sorting stocks based on hybrid tail covariance risk (H-TCR) calculated using the lower $10 \%$ tail of the daily return distribution over the past six months, after screening for liquidity, idiosyncratic volatility, momentum, and reversals. To screen for liquidity, all NYSE/AMEX/NASDAQ stocks are sorted for each month by the ratio of absolute stock return to its dollar volume to determine the NYSE decile breakpoints for the illiquidity measure. Then, we exclude all stocks that belong to the largest NYSE illiquidity decile. To screen for idiosyncratic volatility, all NYSE stocks are sorted for each month by their idiosyncratic volatility to determine the NYSE decile breakpoints for the volatility measure. Then, we exclude all stocks that belong to the highest NYSE volatility decile. To screen for past 6-month winners and losers, all NYSE stocks are sorted for each month by their 6-month cumulative returns from month t-7 to t-2 to determine the NYSE decile breakpoints for momentum (or winners and losers). Then, we exclude the winner (loser) stocks that belong to the highest (lowest) momentum decile. We also screen both momentum winners and losers simultaneously. To screen for past 1-month winners and losers, all NYSE stocks are sorted for each month by their past 1-month return to determine the NYSE decile breakpoints for short-term reversals. Then, we exclude the past 1-month winner (loser) stocks that belong to the highest (lowest) reversal decile. To screen for short-term reversals, we estimate tail covariance risk using daily returns from month t-12 to month t-2, skipping month t-1. Portfolio 1 (10) is the portfolio of stocks with the lowest (highest) H-TCR. The last four rows present the differences in monthly returns and the differences in alphas with respect to the 4-factor Fama-French-Carhart model (FFC4 Alpha) between portfolios 10 and 1, with associated Newey-West t-statistics in parentheses. Average raw and risk-adjusted returns are given in percentage terms.

\begin{tabular}{|c|c|c|c|c|c|c|c|c|}
\hline & Illiquidity & Volatility & $\begin{array}{l}\text { Past 6-month } \\
\text { Winners }\end{array}$ & $\begin{array}{l}\text { Past 6-month } \\
\text { Losers }\end{array}$ & Momentum & $\begin{array}{l}\text { Past 1-month } \\
\text { Winners }\end{array}$ & $\begin{array}{l}\text { Past 1-month } \\
\text { Losers }\end{array}$ & Reversal \\
\hline Low H-TCR & 0.62 & 0.94 & 0.49 & 0.84 & 0.77 & 0.74 & 0.49 & 0.67 \\
\hline 2 & 0.90 & 1.05 & 0.79 & 1.04 & 0.95 & 0.94 & 0.85 & 0.91 \\
\hline 3 & 0.99 & 1.07 & 0.94 & 1.04 & 1.02 & 1.04 & 0.93 & 0.99 \\
\hline 4 & 1.04 & 1.16 & 0.98 & 1.12 & 1.10 & 1.07 & 1.02 & 1.07 \\
\hline 5 & 1.17 & 1.18 & 1.10 & 1.19 & 1.12 & 1.17 & 1.13 & 1.14 \\
\hline 6 & 1.10 & 1.15 & 1.06 & 1.15 & 1.12 & 1.13 & 1.08 & 1.13 \\
\hline 7 & 1.18 & 1.22 & 1.09 & 1.23 & 1.14 & 1.24 & 1.14 & 1.18 \\
\hline 8 & 1.27 & 1.31 & 1.24 & 1.29 & 1.26 & 1.34 & 1.27 & 1.32 \\
\hline 9 & 1.24 & 1.25 & 1.14 & 1.30 & 1.18 & 1.29 & 1.22 & 1.27 \\
\hline High H-TCR & 1.24 & 1.33 & 1.06 & 1.30 & 1.13 & 1.29 & 1.22 & 1.29 \\
\hline Return Diff. & 0.62 & 0.39 & 0.57 & 0.46 & 0.36 & 0.54 & 0.73 & 0.62 \\
\hline t-stat. & $(4.00)$ & (2.86) & (3.97) & $(3.12)$ & $(2.59)$ & $(3.65)$ & $(5.03)$ & $(4.42)$ \\
\hline FFC4 Alpha Diff. & 0.52 & 0.31 & 0.52 & 0.43 & 0.36 & 0.45 & 0.65 & 0.54 \\
\hline t-stat. & (3.64) & (2.37) & $(4.00)$ & (3.07) & $(2.80)$ & (3.24) & $(4.85)$ & $(4.12)$ \\
\hline
\end{tabular}

